\title{
Fermented mulberry (Morus alba) leaves suppress high fat diet-induced hepatic steatosis through amelioration of the inflammatory response and autophagy pathway
}

Mi Rim Lee', Ji Eun Kim¹, Ji Won Park', Mi Ju Kang ${ }^{1}$, Hyeon Jun Choi', Su Ji Bae', Young Whan Choi², Kyung Mi Kim ${ }^{3}$, Jin Tae Hong ${ }^{4}$ and Dae Youn Hwang ${ }^{1 *}$ (D)

\begin{abstract}
Background: A novel extract of mulberry leaves fermented with Cordyceps militaris (EMfC) is reported to exert antiobesity activity, although their molecular mechanism during hepatic steatosis has not verified.

Methods: To investigate the role of inflammation and autophagy during the anti-hepatic steatosis effects of EMfC, we measured alterations in the key parameters for inflammatory response and autophagy pathway in liver tissues of the high fat diet (HFD) treated C57BL/6N mice after exposure to EMfC for 12 weeks.

Results: Significant anti-hepatic steatosis effects, including decreased number of lipid droplets and expression of KIf2 mRNA, were detected in the liver of the HFD + EMfC treated group. The levels of mast cell infiltration, expression of two inflammatory mediators (iNOS and COX-2), and the MAPK signaling pathway were remarkably decreased in the liver of HFD + EMfC treated group as compared to the HFD + Vehicle treated group. Furthermore, a similar inhibitory effect was measured for the expression levels of pro-inflammatory cytokines, including IL-1 $\beta$, IL-6, TNF- $a$ and NF-KB. The expression level of members in the AKT/mTOR signaling pathway (a central regulator in autophagy) was recovered after treatment with EMfC, and autophagy-related proteins (Beclin and LC3-II) were remarkably decreased in the HFD + EMFC treated group compared to the HFD + Vehicle treated group. Moreover, the HFD + EMfC treated group showed decreased transcript levels of autophagy-regulated genes including Atg4b, Atg5, Atg7 and Atg12.
\end{abstract}

Conclusions: Taken together, findings of the present study provide novel evidences that the anti-hepatic steatosis of EMfC is tightly linked to the regulation of the inflammatory response and autophagy pathway in the liver tissue of HFD-induced obesity mice.

Keywords: Anti-hepatic steatosis, Mulberry leaves, Autophagy, Inflammation, Liver

\footnotetext{
* Correspondence: dyhwang@pusan.ac.kr

'Department of Biomaterials Science, College of Natural Resources \& Life Science/Life and Industry Convergence Research Institute, Pusan National University, Miryang 50463, South Korea

Full list of author information is available at the end of the article
} 


\section{Background}

Inflammation is a physiological response generated against various physical, chemical and biological stimuli, in order to maintain homeostasis of the organism [1]. After initial stimulus from the external environment, this process is coordinated by many cell types including leucocytes and tissue-resident macrophages, as well as different inflammatory mediators such as cytokines, chemokines and vasoactive amines [2]. Hepatic inflammation is especially associated with obesity since activation of the inflammatory pathway is an outcome of hepatic steatosis and enhances the hepatic stress response. During obesityinduced liver inflammation, hypertrophic adipocytes secrete free fatty acid, while several immune cells (including Kupffer cells and hepatic stellate cells (HSC)) produce pro-inflammatory cytokines (TNF- $\alpha$, IL-6, IL-1 $\beta$ and IL10) and adipokines (leptin and adiponectin) [3, 4]. The increased fatty acid results in the secretion of inflammatory cytokines and ER stress through the activation of JNK [5, 6]. Simultaneously, excessive accumulation of free fatty acid in the liver inhibits autophagy at the autophagosomelysosome fusion step through dysregulation of the ER calcium pump $[7,8]$.

Anti-inflammatory responses in hepatic steatosis have been widely investigated in the obesity model following exposure to various natural products including salmon cartilage proteoglycan [9], Platycodon grandiflorum-derived saponins (CKS) [10], Acanthopanax koreanum extract [11], large yellow tea [12], and Emblica officinalis [13]. However, limited similar outcomes for anti-obesity activity were observed in the analyses using extracts of fermented natural products. The extract of fermented Moringa oleifera decreases hepatic lipid accumulation, upregulates lipid metabolic genes, as well as decreases pro-inflammatory cytokine (IL-6 and IL-12) mRNA expressions in the liver of HFD-induced obesity model [14]. Similar effects were observed in the HFD-induced Wistar rats after treatment with fermented Fuzhuan tea. Increased mRNA levels of TNF- $\alpha$ observed in the adipose tissue of HFD animals were inhibited by Fuzhuan tea treatment [15]. Fermented soybean products also suppress the expression of NF- $\mathrm{kB}$-induced inflammatory proteins, including COX-2, iNOS and VCAM-1, in kidneys of HFD-induced SD rats [16].

Meanwhile, non-alcoholic fatty liver disease (NAFLD) has been well defined as an accumulation condition of excessive fat in the liver tissue without another clear causes such as alcohol intake [17]. This disease contributes to various metabolic syndromes such as obesity, diabetes, insulin resistance, hyperlipidemia and hypertension [18]. Also, NAFLD classifies into simple steatosis and nonalcoholic steatohepatitis (NASH) depending on the determination of inflammation and liver cell damage. Of these two types, NASH with hepatic cellular injury and inflammation effectively progresses to fibrosis, cirrhosis and liver cancer [19]. Until now, various candidates including chemical compounds and natural products have been reported to have potential for the treatment of NASH. They included cytoprotective agents (ursodeoxycholic acid), antioxidants (vitamin E and betaine), antidiabetic agent (thiazolidinediones and troglitazone) and antihyperlipidemic agent (bezafibrate) [2025]. However, many issues remain unresolved extending the spectrum and verifying the action mechanism of treatment drugs for NASH. To overcome these issues, natural products have been received a great attention as one of the important basic materials because they may effectively improve symptoms and severity of NAFLD without significant adverse side effects [26-28].

Furthermore, the anti-hepatic steatosis of natural products is tightly linked with the activation of autophagy. After exposure to several products, including bergamot polyphenol fraction (BPF), quercetin, metformin and Eucommia ulmoides leaf extract, the autophagy markers and their signaling pathway were remarkably recovered in the obesity model [29-32]. However, the EMfCs effects on the autophagy response has not been analyzed in the liver tissue of HFD-induced obesity model during anti-hepatic steatosis, although some evidences for their anti-obesity effects have been recently reported. In our previous studies, anti-obesity effects and action mechanism of EMfC have been investigated in adipocytes and obesity model. EMfC stimulated the lipolysis via the increase of cAMP concentration and free glycerol level in 3 T3-L1 cells and the primary adipocytes of Sprague Dawley (SD) rats [33]. Also, EMfC treatment for 12 weeks induce the significant decrease on the number of lipid droplets, peroxisome proliferator-activated receptor- $\gamma$ (PPAR- $\gamma$ ) mRNA, adipocyte protein 2 (aP2) mRNA, FAS cell surface death receptor mRNA as well as the increase on the phosphorylation of perilipin and hormone-sensitive lipase, and the expression of adipose triglyceride lipase in the liver tissue of HFD-induced obese C57BL/6N mice [32]. A similar effect was observed on the amount of abdominal fat, the size of adipocytes, low-density lipoprotein (LDL) level, triglyceride level and total cholesterol (TC) level in HFD-induced obese C57BL/6N mice [32]. The anti-obesity effect of EMfCs in the liver tissue was reported to be linked to the regulation of ER stress and ER stress-induced apoptosis [34]. Therefore, above previous results about beneficial effects of EMfCs show the need for additional mechanism study related to anti-hepatic steatosis in HFD-induced obese C57BL/6N mice.

In this study, we investigated the regulatory mechanism of the inflammatory responses and autophagy during the anti-hepatic steatosis activity of EMfC in a C57BL/ $6 \mathrm{~N}$ mice with HFD-induced obesity. The results of the present study show that the anti-hepatic steatosis activity 
of EMfC may closely related to suppression of the inflammatory response and recovery of autophagy regulation.

\section{Methods}

\section{Preparation and fermentation of EMfCs}

EMfCs was prepared using the materials and methods described in the previous study [20]. Dried samples of mulberry leaves harvested from plantations in the Sangju district of Korea and identified by Professor Young Whan Choi, one author of our study. These samples were deposited as voucher specimens (accession number Mul-PDRL-1) at the herbarium of the Department of Horticultural Bioscience at College of Natural Resources and Life Science in Pusan National University. The $C$. militaris and the silkworm pupae powder used for fermentation provided from Professor Sang Mong Lee of the Department of Life Science and Environmental Biochemistry and the Jeongeup Agriculture Cooperative Federations for Silkworm Farming (Jeongeup, Korea).

After sterilizing the mulberry powder at $121{ }^{\circ} \mathrm{C}$ for $60 \mathrm{~min}$, these powders were mixed with $50 \%$ silkworm powder (SWP) and $10 \%$ C. militaris $(\mathrm{v} / \mathrm{w})$, and subsequently fermented in a shaking incubator (\#SI-600R, Medline Scientific Co., Oxfordshire, UK) at $130 \mathrm{xg}$ and $25{ }^{\circ} \mathrm{C}$ for 4 weeks. Also, the fermented mixture of mulberry powder was harvested from the glass flask and applied to extraction procedure in $95 \% \mathrm{EtOH}$. Extraction mixture containing the fermented mixture and the solvent (fixed ratio 1:10) was sonicated for 1 h using a JAC ultrasonic device (KODO, Hwangseong, Korea) and collected the supernatant after centrifugation at $13,000 \mathrm{xg}$ for $20 \mathrm{~min}$. This resultant supernatant was filtered, evaporated and lyophilized under previously reported conditions to prepare EMfCs [32]. Finally, EMfC were completely dissolved in dimethyl sulfoxide (DMSO)(\#D2660, Sigma-Aldrich Co., St Louis, MO, USA) at a concentration of $50 \mathrm{mg} / \mathrm{mL}$ in $1 \%$ diluted DMSO solution based on previous studies showing non-toxic concentrations of DMSO to prevent animal toxicity [35].

\section{Experimental scheme for mice study}

In vivo animal study was carried out as described in previous study using HFD-induced model. Experimental protocol for the obesity model was carefully reviewed based on ethical and scientific care guideline, and approved by the Pusan National University-Institutional Animal Care and Use Committee (PNU-IACUC; Approval Number PNU-2017-1519). Male C57BL/6N mice with eight weeks of age were obtained from Samtako BioKorea Inc. (Osan, Korea). All mice used study were provided with ad libitum access to water and an irradiated standard chow diet (Samtako BioKorea Co., Osan, Korea) containing crude protein $(25.43 \%)$, moisture (12.5\%), crude fat $(6.06 \%)$, crude ash $(5.31 \%)$, crude fiber (3.9\%), calcium (1.14\%) and phosphorus (0.99\%). During all experimental period, they were breed in a specific pathogen-free (SPF) environmental condition under a strict light cycle (lights on at 08:00 A.M. and off at 08:00 P.M.) at $23 \pm 2{ }^{\circ} \mathrm{C}$ temperature and $50 \pm$ $10 \%$ relative humidity. Also, all mice were housed solid-bottom cage with wood shavings at the Pusan National University-Laboratory Animal Resources Center, which is accredited by the Korea Ministry of Food and Drug Safety (MFDS; Accredited Unit 000231) and Association for Assessment and Accreditation of Laboratory Animal Care (AAALAC) International (Accredited Unit 001525). The microbiological status of all mice have regularly monitored by animal health report that detected virus (4 species), bacteria and mycoplasma (7 species), and parasite (3 species).

Following acclimation for 1 week, the C57BL/6N mice $(n=28)$ were randomly divided into one of four experimental groups (7 mice/group): (1) NO treated group, (2) HFD + Vehicle (Olive oil + 1\% DMSO) treated group, (3) HFD + OT treated group and (4) HFD + EMfC treated group. The animal number for each group was calculated based on the anti-obesity effects of mulberry leaves according to Ann et al. using G power 3.1 [36]. The No treated group fed a standard diet, while three HFD treated groups fed HFD containing 60\% kcal fat (\#D12492, Research Diets, Inc., New Brunswick, USA) for 12 weeks. HFD + EMfC treated group were orally administered 50 $\mathrm{mg} / \mathrm{kg}$ body weight EMfC five times a week at $10 \mathrm{~A} . \mathrm{M}$, while HFD + OT and HFD + Vehicle treated group was received $10 \mathrm{mg} / \mathrm{kg}$ Orlistat (OT) or olive oil + 1\% DMSO solution in the same way. But, No treated group did not receive any treatment during all experimental period. At $24 \mathrm{~h}$ after the final treatment, mice of subset groups were euthanized using $\mathrm{CO}_{2}$ gas in euthanasia chamber; tissue samples for analyses were subsequently collected and stored in Eppendorf tubes at $-70{ }^{\circ} \mathrm{C}$. Five mice for liver analysis were selected from total mice of each subset group based on the increase rate of body weight and fat accumulation in the liver tissue.

\section{Measurement of organs weight, body weight and food efficiency}

The weight of organs and body in all mice of No and HFD treated groups was measured by an electronic balance (Mettler Toledo, Greifensee, Switzerland) after the treatment of EMfC for 12 weeks. Food efficiency ratio was calculated using the following formula [37]: 
Food efficiency ratio $=($ Body weight gain $(\mathrm{g}) /$ Food intake $(\mathrm{g})) \times 100$

\section{Histopathology for liver tissue}

After collecting the liver tissues from mice of subset groups, these samples were fixed in $10 \%$ formalin solution for $48 \mathrm{~h}$. The meddle region of second lob in the liver tissue were carefully trimmed from the fixed liver tissues, and then embedded into paraffin blocks. Following sectioning the tissue block into $4 \mu \mathrm{m}$ thick slices, the liver sections were stained with hematoxylin and eosin (H\&E) solution (Sigma-Aldrich Co.) and Masson's trichrome (M\&T) staining solution (Sigma-Aldrich Co.), and microscopically examined at 400× magnification for histopathological features. The pathological features and steatosis scoring of liver tissue were characterized by Professor Beum Seok Han, a pathologist, at the Department of Pharmaceutical Engineering, Hoseo University, Korea. In this histopathological scores system, scoring was evaluated based on the number of lipid droplet (13 ), fibrosis level (1-4) and inflammation (1-3) as described in previous study [38].

Meanwhile, mast cells infiltrated into liver tissue was stained with toluidine blue as described in previous study [39]. After deparaffinization and dehydration, liver sections on the slide glass were stained with $0.25 \%$ toluidine blue solution (Sigma-Aldrich Co.) and the presence of mast cells were observed by light microscopy. The number of cells per specific area was counted using the Leica Application Suite (Leica Microsystems, Wetzlar, Germany).

To stain oil red $\mathrm{O}$, the liver tissue collected from HFD-induced obesity mice were directly embedded in OCT compound. This tissue blocks were frozen and sectioned into $10 \mu \mathrm{m}$ thick slice. The liver sections on glass slides were fixed in $10 \%$ formalin solution for $10 \mathrm{~min}$ and subsequently treated with $60 \%$ isopropanol for $1 \mathrm{~min}$, and then stained with Oil Red O solution (Sigma-Aldrich Co.) at $37{ }^{\circ} \mathrm{C}$ for $15 \mathrm{~min}$. Following treatment of $60 \%$ isopropanol and $\mathrm{dH}_{2} \mathrm{O}$, the liver tissues were counterstained with Mayer's hematoxylin solution and observed by light microscopy.

\section{Quantitative real time (qRT)-PCR analysis}

The frozen liver tissues of all mice were homogenized with Polytron PT-MR 3100 D Homogenizer (Kinematica AG, Lusern, Switzerland) in RNA Bee solution (Tet-Test Inc., Friendswood, TX, USA) based on manufacture's protocol. After ethanol precipitation, total RNAs were harvested by centrifugation at 10,000 $\mathrm{xg}$ for $15 \mathrm{~min}$, after which their concentration was determined by Nano-300 Micro-Spectrophotometer (Allsheng Instruments Co. Ltd., Hangzhou, China). The purity of total RNA was determined using the ratio of the absorbance at 260 and $280 \mathrm{~nm}$. A value of $1.8-2.0$ at an A260/A280 determined that the RNA has sufficient purity to be used in qRT-PCR analysis. Total complementary DNA (cDNA) against mRNA was synthesized using 200 units of Invitrogen Superscript II reverse transcriptase (Thermo Scientific, Wilmington, DE, USA). qRT-PCR was conducted with the cDNA template $(1 \mu \mathrm{L})$, 2x Power SYBR Green ( $6 \mu \mathrm{L}$; Toyobo Life Science, Osaka, Japan), several following specific primers and appropriate buffer. The primer sequences to measure the expression level of target genes were as follows: IL-1 $\beta$, sense $5^{\prime}$-GCA CAT CAA CAA GAG CTT CAG GCA G-3' and antisense 5' -GCT GCT TGT GAG GTG CTG ATG TAC-3'; IL-6, sense 5' -TTG GGA CTG ATG TTG TTG ACA-3' and anti-sense $5^{\prime}$-TCA TCG CTG TTG ATA CAA TCA GA-3'; TNF- $\alpha$, sense 5'-CCT GTA GCC CAC GTC GTA GC-3' and anti-sense 5' ${ }^{\prime}$-TTG ACC TCA GCG CTG ACT TG-3'; NF-kB, sense 5' -TGA TGA CAT ACT CCC ACA AG-3' and anti-sense 5' - CAA TAT CCC CAG ACC TAA C-3'; iNOS, sense 5'-CAC TTG GAG TTC ACC CAG $\mathrm{T}^{-3}$ ' and anti-sense $5^{\prime}$-ACC ACT CGT ACT TGG GAT GC-3'; COX-2, sense 5'-CAG GTC ATT GGT GGA GAG GTG TAT $\mathrm{C}^{-3}$ ' and anti-sense $5^{\prime}$-CCA GGA GGA TGG AGT TGT TGT AGA G-3'; Atg4b, sense $5^{\prime}$-CTA TGT GGA GAC GCT GAA GCA CTG TTT C-3' and anti-sense $5^{\prime}$-CTC TCC AGT CTC TCT ACA TCA GAA GAG-3'; Atg5, sense 5' -CCA AGA GTC AGC TAT TTG ACG-3' and anti-sense $5^{\prime}$-TCC AAG GAA GAG CTG AAC TTG-3'; Atg7, sense 5' -CCT TGC TCA AAC ACT ACA GTG-3' and anti-sense 5' -TGC TAT GTG TCA CGT CTC TAG-3'; Atg12, sense 5'CCA TCC AAG GAC TCA TTG AC-3' and anti-sense 5' - TTG CAG TAA TGC AGG ACC AG-3'; Klf2, sense 5' -CTG GAA TTG AAC CAC AGA GGA CTG AC-3' and anti-sense 5 '-GTC ACA GTC TGG ACA CTG GAA AGG TTT G-3'; $\beta$-actin, sense $5^{\prime}$-TGG AAT CCT GTG GCA TCC ATG AAA C-3' and anti-sense 5' -TAA AAC GCA GCT CAG TAA CAG TCC G-3'. PCR analyses were conducted at $95{ }^{\circ} \mathrm{C}$ for $15 \mathrm{~s}$ (denaturation), $64{ }^{\circ} \mathrm{C}$ for $30 \mathrm{~s}$ (annealing), and $72{ }^{\circ} \mathrm{C}$ for $60 \mathrm{~s}$ (extension) for $40 \mathrm{cy}$ cles. These reactions were run in StepOne ${ }^{\mathrm{m}}$ Real-Time PCR System (Applied Biosystem, Poster city, CA, USA) and relative level of each gene was quantified based on a relative standard curve and comparative Ct $(\Delta \Delta \mathrm{Ct})$ using StepOne Plus ${ }^{\text {Th }}$ Systems software (Applied Biosystem,) as described in previous study [40].

\section{Western blot analysis}

Total proteins from liver tissue $(50 \mathrm{mg})$ were prepared using the Pro-Prep Protein Extraction Solution (Cat. No. 17081, Intron Biotechnology Inc., Seongnam, Korea). After the collection of proteins homogenates with centrifugation at $13,000 \mathrm{rpm}$ for $5 \mathrm{~min}$, 
the protein concentrations of each group were determined using a SMARTTM Bicinchoninic Acid Protein Assay Kit (Cat. No. 23225, Thermo Fisher Scientific Inc.). Total proteins $(30 \mu \mathrm{g})$ were electrophoresed on $4-20 \%$ sodium dodecyl sulfatepolyacrylamide gel electrophoresis (SDS-PAGE) for $2 \mathrm{~h}$, and they were subsequently transferred to nitrocellulose blotting membranes with a $0.45 \mu \mathrm{m}$ pore size (Cat. No. 10600003, GE Healthcare, Little Chalfont, UK) for $2 \mathrm{~h}$ at $40 \mathrm{~V}$. This membrane was incubated separately, overnight at $4{ }^{\circ} \mathrm{C}$, with specific primary antibodies: anti-JNK antibody (\#9252 s, Cell signaling Technology, Danvers, MA, US), anti-p-JNK antibody (\#9251 s, Cell signaling Technology), anti-ERK antibody (\#sc-94, Santa Cruz Biotechnology, Dallas, Texas, USA), anti-p-ERK antibody (\#sc-7383, Santa Cruz Biotechnology), anti-p38 antibody (\#9212s, Cell Signaling Technology), anti-p-p38 antibody (\#9211 s, Cell Signaling Technology), anti-Beclin antibody (\#3738 s, Cell Signaling Technology), anti-LC3-I/II antibody (\#3868 s, Cell Signaling Technology), anti-PI3K antibody (\#4292 s, Cell Signaling Technology), anti-p-PI3K antibody (\#4228 s, Cell Signaling Technology), anti-AKT antibody (\#9272 s, Cell Signaling Technology), anti-p-AKT antibody (\#4058 s, Cell Signaling Technology), anti-mTOR antibody (\#2972 s, Cell Signaling Technology), anti-p-mTOR antibody (\#2971 s, Cell Signaling Technology), and anti- $\beta$ actin antibody (\#4967S, Cell Signaling Technology). After then, the probed membranes were then washed with washing buffer $(137 \mathrm{mM} \mathrm{NaCl}, 2.7 \mathrm{mM} \mathrm{KCl}, 10 \mathrm{mM}$ $\mathrm{Na}_{2} \mathrm{HPO}_{4}$, and $0.05 \%$ Tween 20 ), followed by incubation with 1:1000 diluted horseradish peroxidase (HRP)-conjugated goat anti-rabbit IgG (Cat. No. G21234, Invitrogen) at room temperature for $1 \mathrm{~h}$. Each protein blotted membrane was developed using the Amersham ${ }^{\mathrm{Tm}}$ ECL Select ${ }^{\mathrm{Tm}}$ Western Blotting detection reagent (Cat. No. RPN2235, GE Healthcare). Finally, the chemiluminescence signals that derived from specific protein bands were measured using FluorChemi ${ }^{\circ}$ FC2 (Alpha Innotech Co., San Leandro, CA, USA).

\section{Statistical analysis}

The statistical significance between the groups was analyzed with One-way Analysis of Variance (ANOVA) (SPSS for Windows, Release 10.10, Standard Version, Chicago, IL, USA) followed by Tukey post hoc t-test for multiple comparisons. All values are presented as the means $\pm \mathrm{SD}$, and a $p$ value $(p<0.05)$ is determined as statistically significant.

\section{Results \\ Verification of anti-hepatic steatosis activity of EMfC}

Firstly, we conformed the anti-hepatic steatosis activity of EMfC in liver tissue of HFD-induced obese mice through the regulation of weight gain as same as previous study (Table 1). In order to verify the inhibitory effect of EMfC on hepatic steatosis, the steatosis score based on lipid droplet number, fibrosis level and inflammation level were calculated in H\&E, M\&T and Oil Red $\mathrm{O}$ stained liver sections after exposure to EMfC. The number and size of lipid droplets were measured in $\mathrm{H} \& \mathrm{E}$ stained liver sections after exposure to EMfC. The HFD + Vehicle treated group had the number of lipid droplets and high average area of single droplet in the specific area. However, the levels were decreased in the HFD + EMfC and HFD + OT treated groups as compared to the HFD + Vehicle treated group, although the decrease rates differed. Also, the remarkable accumulation in lipid droplets was detected in Oil Red $\mathrm{O}$ stained liver tissue of HFD + EMfC and HFD + OT treated mice. A similar decrease was observed on the inflammation level after EMfC treatment, while the fibrosis level was constantly maintained in all experimental groups (Fig. 1a). Therefore, total score in HFD + Vehicle treated group was decreased in the HFD + EMfC treated groups (Table 2).

A similar effect was observed for levels of Klf2 (Krüppel-like Factor 2) transcript in the subset group; increased levels of Klf2 in the HFD + Vehicle treated group were remarkably recovered after exposure to

Table 1 Body weight and food efficiency in HFD-induced obese mice treated with EMfC

\begin{tabular}{lllll}
\hline Category & No & HFD & & OT \\
\cline { 4 - 5 } & & Vehicle & & EMfC \\
\hline Body weight (g) & & & $24.39 \pm 1.99$ & $24.16 \pm 1.85$ \\
$\quad$ Initial & $24.13 \pm 1.86$ & $24.91 \pm 2.16$ & $45.50 \pm 2.76^{*, \#}$ & $44.99 \pm 1.47^{*, \#}$ \\
$\quad$ Final & $27.14 \pm 2.26$ & $51.60 \pm 1.95^{*}$ & 21.11 & 20.83 \\
$\quad$ Change & 3.01 & 26.69 & $3.05 \pm 0.26^{*}$ & $3.18 \pm 0.41^{*}$ \\
Abdominal fat weight (g) & $0.63 \pm 0.22$ & $3.32 \pm 0.23^{*}$ & $1.94 \pm 0.43^{*, \#}$ & $2.04 \pm 0.26^{*, \#}$ \\
Liver weight (g) & $1.05 \pm 0.13$ & $2.91 \pm 0.52^{*}$ & $0.167 \pm 0.077^{*, \#}$ & $0.150 \pm 0.004^{*, \#}$ \\
Food efficiency ratio (\%) & $0.046 \pm 0.019$ & $0.227 \pm 0.025^{*}$ &
\end{tabular}

Asterisk symbol (*) indicate significant $P<0.05$ compared with the No treated group. Sharp symbol (\#) indicates significant $P<0.05$ compared with the HFD + Vehicle treated group 


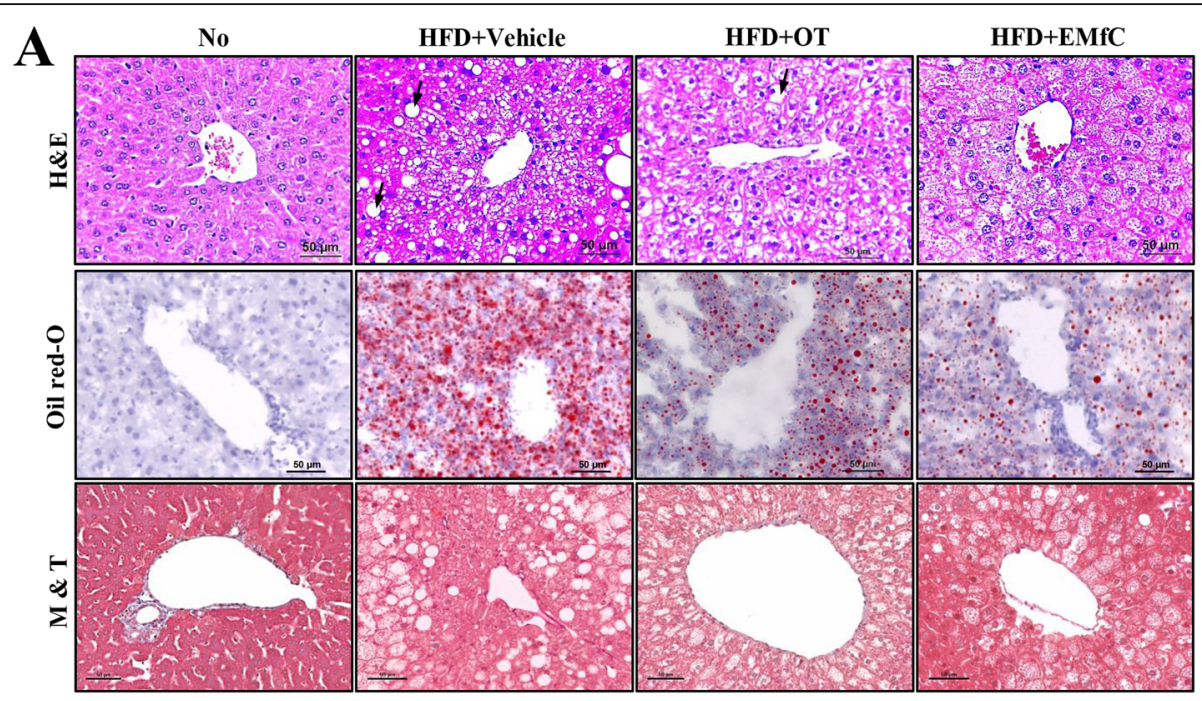

B
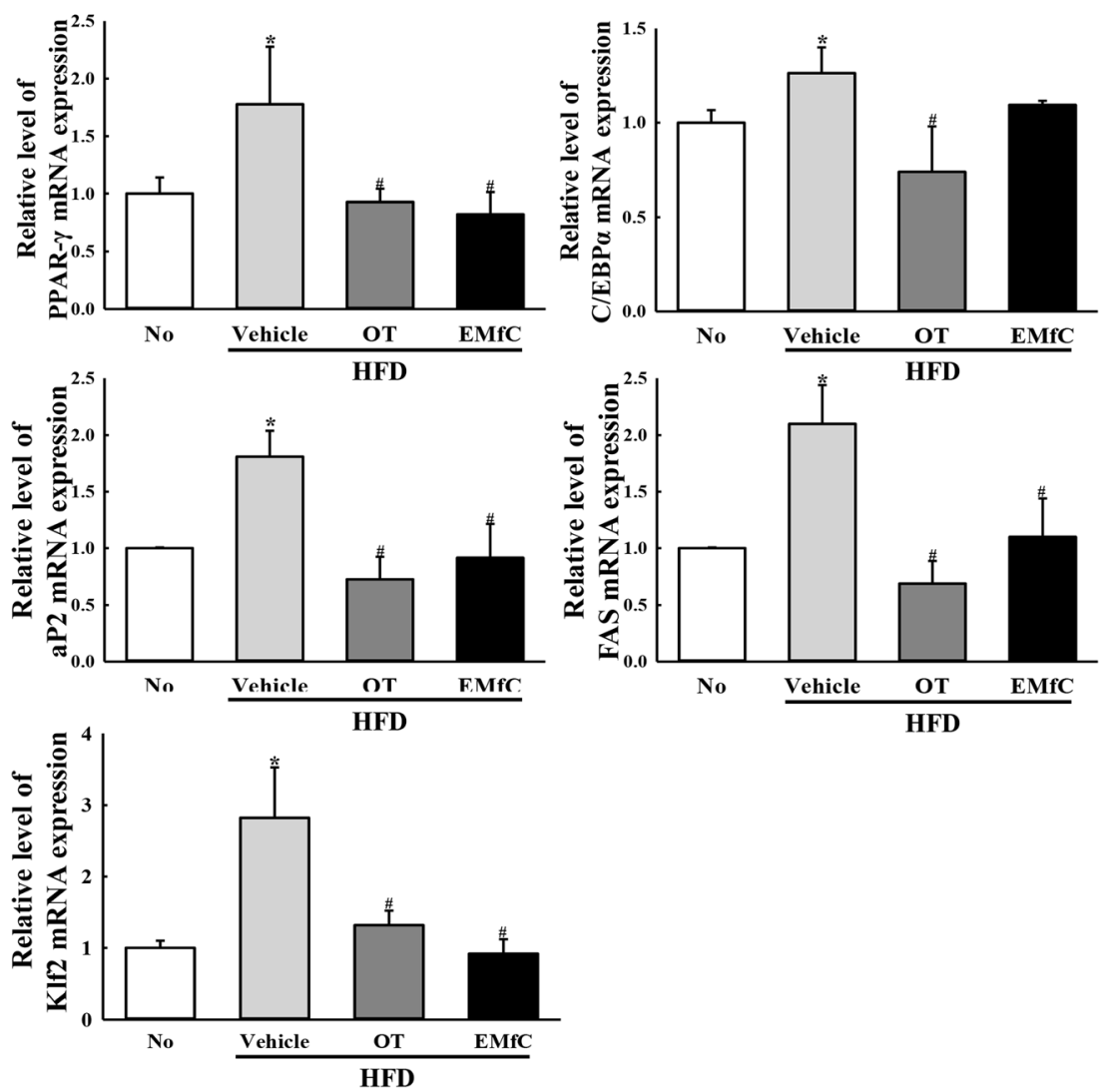

Fig. 1 Fat accumulation on the liver histopathology. a After embedding and sectioning the fixed liver tissue of all mice, hematoxylin and eosin (H\&E) and Masson's trichrome (M\&T) stained liver sections are shown at 400x magnification. Frozen sections of liver tissue were stained with Oil Red $O$ to detect intracellular lipid droplets after fixation. Three to five mice per group were used for the preparation of the tissue sections, and H\&E, M\&T and Oil Red O staining was analyzed in duplicate in each liver tissue. b After exposure to EMfC (50 mg/kg) for 12 weeks, the levels of PPAR-Y, C/EBPa, FAS, aP2 and KIf2 mRNA in the total transcripts of liver were measured by qRT-PCR analyses using their specific primers. The relative levels of the PPAR, C/EBPa, FAS, aP2 and KIf2 mRNA were calculated based on the intensity of $\beta$-actin as an endogenous control. Three to five mice per group were used in the preparation of the total RNAs, and QRT-PCR analyses was assayed in duplicate for each sample. Data represents the mean \pm SD. Asterisk symbol $\left(^{*}\right)$ indicates significance $P<0.05$ as compared to the No treated group. Sharp symbol (\#) indicates significant $P<0.05$ compared to the HFD + Vehicle treated group 
Table 2 Hepatic steatosis score in HFD-induced obese mice treated with EMfC

\begin{tabular}{lllll}
\hline Category & No & HFD & \\
\cline { 3 - 5 } & & Vehicle & OT & EMfC \\
\hline Number of lipid droplet & 0 & 3 & 1 & 1 \\
Fibrosis level & 0 & 0 & 0 & 0 \\
Inflammation level & 0 & 1 & 1 & 1 \\
Total & 0 & 4 & 2 & 2 \\
\hline
\end{tabular}

After staining liver section with $\mathrm{H} \& \mathrm{E}$, Oil red $\mathrm{O}$ and M\&T solution, the histopathological scores was evaluated based on the number of lipid droplet (1-3), fibrosis level (1-4) and inflammation (1-3) as described in materials and methods

EMfC (Fig. 1b). These results indicate that EMfC successfully inhibits hepatic steatosis in the liver tissue of HFD-induced obesity mice.

\section{Attenuation effects of EMfC on the regulation of HFD- induced inflammatory responses during anti-hepatic steatosis}

To investigate the effect of EMfC on the regulation of inflammatory response during anti-hepatic steatosis, alterations on mast cells infiltration, expression of inflammatory mediators, inflammatory stimuli-induced MAPK pathway activation, and inflammatory cytokine transcriptions were measured in the liver tissue after administration of EMfC. Remarkably higher numbers of mast cells were stained blue in the HFD + Vehicle treated group than the No treated group. However, the numbers were significantly decreased in the HFD + OT and HFD + EMfC treated groups ( $72 \%$ and $48 \%$, respectively) (Fig. 2a). A similar pattern was observed for mediators in the iNOS-mediated COX-2 induction pathway after EMfC treatment. The levels of iNOS and COX-2 gene transcripts were higher in the HFD + Vehicle treated group than in the No group, but significantly decreased in the HFD + OT and HFD + EMfC treated groups (Fig. $2 b)$. Furthermore, the alteration of iNOS and COX-2 transcript levels were accompanied by a change in MAPK pathway. The phosphorylation levels of ERK, JNK and p38 were variably higher after HFD administration as compared to No treatment. Of the three members, the phosphorylation levels of JNK and p38 were remarkably decreased after EMfC treatment, while the level of ERK was increased (Fig. 3). Moreover, the transcription levels of anti- and pro-inflammatory cytokines were completely reflected as alterations in the MAPK pathway; the transcription levels of IL- $1 \beta$, IL- 6 , TNF- $\alpha$ and NF- $\mathrm{kB}$ were also very similar in the subset group. The enhanced levels of the four cytokines were decreased in the HFD + OT and HFD + EMfC treated groups, although the rate of decline was varied for each gene (Fig. 4). Taken together, these results indicate that the anti-hepatic steatosis effect of EMfC is associated with the suppression of inflammatory responses in the liver of HFD-induced obesity model.

\section{Regulation of autophagy and PI3K/AKT/mTOR signaling pathway during anti-inflammatory response of EMfC}

We next investigated the role of autophagy in the sequential inhibition of inflammatory response by applying EMfC to hepatic steatosis of HFD-induced obesity model. Significant alterations were observed in the PI3K/AKT/mTOR signaling pathway after treatment with EMfC. The decrease in the phosphorylation levels of PI3K and AKT in the HFD + Vehicle treated group were observed to increase in the HFD + EMfC treated group, whereas the reverse was true for the phosphorylation level of mTOR (Fig. 5). Furthermore, we investigated whether the alteration of $\mathrm{PI} 3 \mathrm{~K} / \mathrm{AKT} / \mathrm{mTOR}$ signaling pathway after EMfC exposure is accompanied with an activation of autophagy. To achieve this, the expression levels of genes and proteins included in autophagic flux were examined in the liver of HFD + EMfC treated mice because these proteins were degraded by autophagy. The proteins levels of Beclin and LC3 were higher in the HFD + Vehicle treated mice than the No treated group. However, levels were significantly decreased in the HFD + OT and HFD + EMfC treated groups (Fig. 6). In addtion, a similar response was observed in the mRNA expression levels of four autophagy related genes including Atg4b, Atg5, Atg7, and Atg12. Under conditions of obesity, levels of all genes were increased in the HFD + Vehicle group as compared to the No treated group. However, the transcript levels of these genes were remarkably recovered in the HFD + OT and HFD + EMfC groups, although at varied degrees (Fig. 7). These results indicate that activation of the autophagy machinery in hepatic steatosis of HFD-induced obesity model is associated with the anti-inflammatory response of EMfC, including the AKT/mTOR signaling pathway and regulator proteins.

\section{Discussion}

The beneficial effects of mulberry leaves have been investigated for the regulation of lipid metabolism, although there are few studies for inflammation and autophagy. Previous studies report that the extract of these leaves downregulate the lipogenesis-related genes in rats after 7 weeks treatment, and remarkably reduces the expression of the lipoprotein-related protein and accumulation of lipid in 3T3-L1 adipocytes [34]. Also, the extract of mulberry leaves induces decrease in the adipocyte differentitation in white adipose tissue of $\mathrm{db} / \mathrm{db}$ mice through suppression of oxidative stress [41, 42]. Fermented leaves were reported to prevent fat 

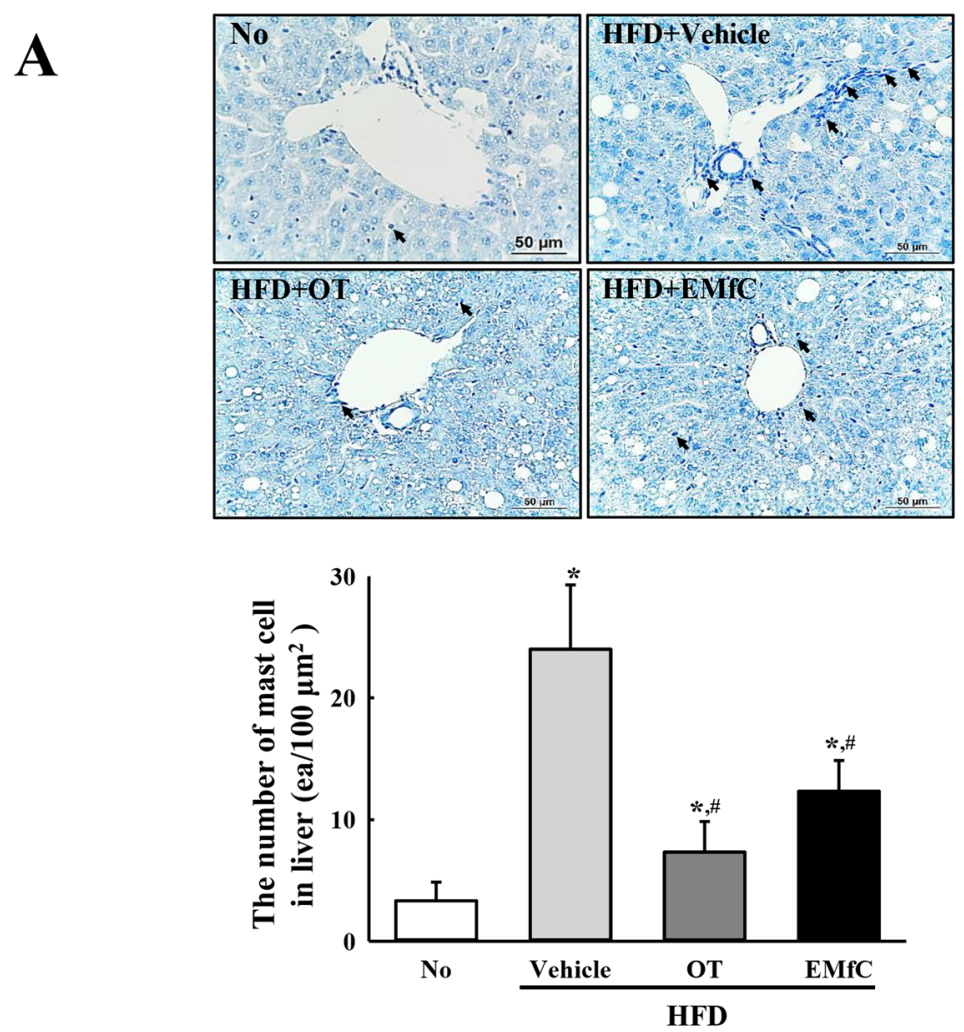

B
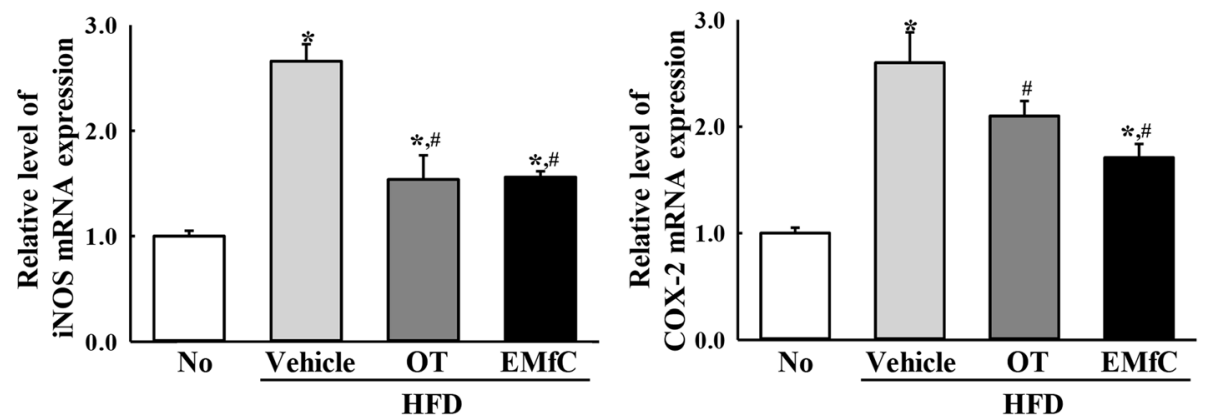

Fig. 2 Infiltration of mast cells and expression levels of inflammatory mediators. a The infiltrated mast cells in the tissue sections of liver collected from HFD + EMfC treated mice were stained with toluidine blue, followed by observed and counted at 400x magnification. The arrow head in histological image indicates mast cells infiltrated into the liver tissue. Three to five mice per group were used for the preparation of the tissue sections, and toluidine blue staining and cell counting was analyzed in duplicate in each liver tissue. $\mathbf{b}$ The levels of iNOS and COX-2 mRNA in the total transcripts of liver were measured by qRT-PCR analyses using their specific primers. The relative levels of the iNOS and COX-2 mRNA were calculated based on the intensity of $\beta$-actin as an endogenous control. Three to five mice per group were used in the preparation of the total RNAs, and qRT-PCR analyses was assayed in duplicate for each sample. The values of data represent the mean \pm SD. Asterisk symbol $(*)$ indicates significant $P<0.05$ compared to the No treated group. Sharp symbol (\#) indicates significant $P<0.05$ compared to the HFD + Vehicle treated group

accumulation in the HFD-induced obese C57BL/6 mice through stimulation of lipolysis and by inhibition of lipogenesis [32]. In this study, we investigated the molecular mechanism of inflammation and autophagy, based on the inhibitory effect exerted by EMfC for fat accumulation. We believe that the current study results provide first evidence of the molecular mechanism for anti-hepatic steatosis, where EMfC may be associated with the regulation of inflammation and autophagy in the HDF-induced obesity model.

In a variety of studies to evaluate anti-obesity effect of natural products, several chemical drugs have been used as positive control for obesity management. Among these, OT has been well known an inhibitor of the gastrointestinal 

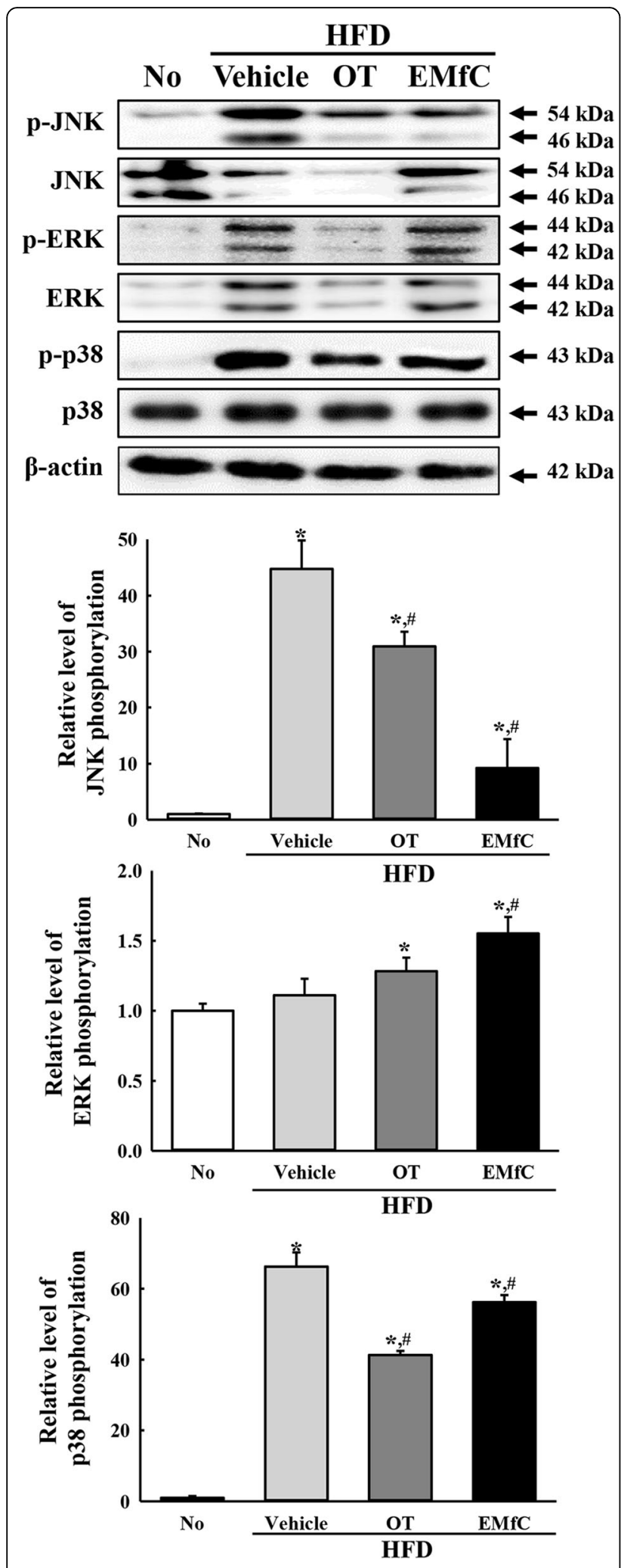

Fig. 3 Expression of MAPK signaling pathway in liver tissue. Western blot analysis measured the p-JNK, JNK, p-ERK, ERK, p-p38, p38 and $\beta$ actin proteins in total liver homogenate using their specific antibodies. Band intensity of each protein were measured using an imaging densitometer, and the expressions of the six proteins were calculated relative to the intensity of $\beta$-actin protein. Three to five mice per group were used in the preparation of liver homogenates, and Western blot analysis was assayed in duplicate for each sample. Data represent the mean \pm SD. Asterisk symbol $\left(^{*}\right)$ indicates significant $P<0.05$ compared to the No treated group. Sharp symbol (\#) indicates significant $P<0.05$ compared to the HFD + Vehicle treated group

lipase that decrease with $30 \%$ of fat accumulation, body weight and improve cardiovascular risk factors of obese patients [43-45]. Also, OT treatment is associated with significant improvement in blood pressure, TC, LDL, the incidence of type II diabetes and the insulin sensitivity [4648]. In HFD-induced obesity model, OT was significantly decreased the level of adipogenesis regulators including PPAR, C/EBP, FAS and aP2, while it increased the phosphorylation of perilipin and expression of ATGL [32]. Although OT has above therapeutic effects, it cannot induce any serious systemic side effects during long periods of intake [49]. Because of these properties on toxicity and therapeutic mechanism, OT is most commonly used as a positive control in many studies identifying novel natural products with anti-obesity activity. Therefore, our study had selected OT as standard drug for evaluation of EMfC. On the other hand, metformin has been considered as one of another control drugs because it decreases hyperinsulinemia, insulin resistance and adiposity in obesity and type II diabetes [50-52].

Among all the inflammatory cytokines, IL-6 is considered to a useful marker for obesity-induced inflammation and is secreted from Kupffer cells and HSC of the liver tissue $[53,54]$. IL- 6 and TNF- $\alpha$ enhance the hepatic production of $\mathrm{C}$-creative protein (CRP), which is increased under conditions of obesity [55]. Furthermore, other cytokines such as IL-1 $\beta$, OSM (oncostatin M) and LIF (leukaemia inhibitory factor) are induced with the production of CRP (C-reactive protein) [56]. A significant decrease of IL-6 and TNF- $\alpha$ levels were observed in the liver of HFDinduced obesity model after exposure to several natural products [11-13] and their fermented products [14]. In our study, treatment with EMfC prepared by fermentation, suppresses the IL- 6 and TNF- $\alpha$ levels in the liver of HFD-induced C57BL/6J mice. The results of the present study were agree with earlier studies that report suppression of the expression of key inflammatory cytokines in the HFD-induced model by natural products, although the suppression rates were varied.

Previous pharmacological studies have demonstrated the potential of herbal medicine extracts and natural products in regulating the autophagy flux during 

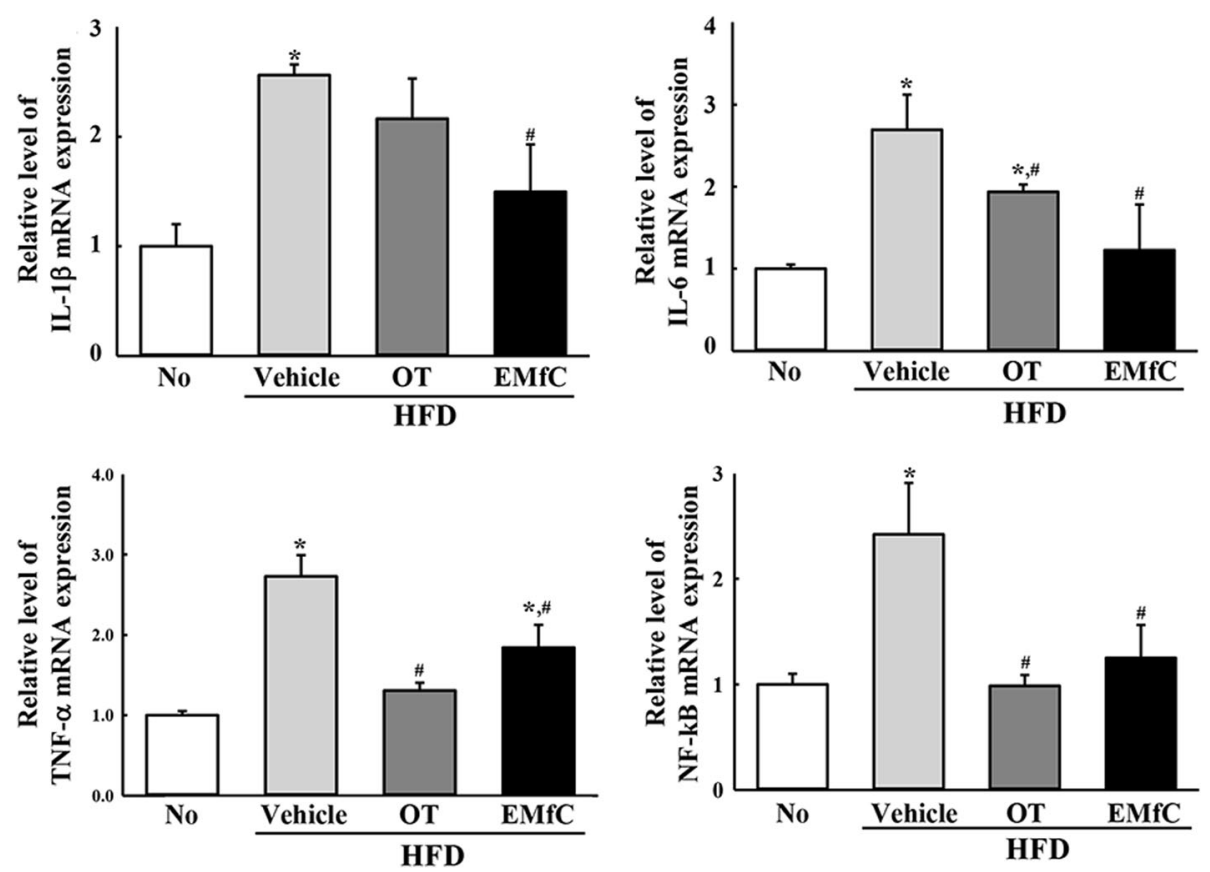

Fig. 4 Expression level of pro- and anti-inflammatory cytokines in liver tissue. The levels of IL-1 $\beta, I L-6, T N F-a$ and NF-KB mRNA in the total transcripts of liver tissue were measured by qRT-PCR analyses using their specific primers. The relative levels of the IL-1 $\beta, I L-6, T N F-a$ and NF-KB mRNA were calculated based on the intensity of $\beta$-actin as an endogenous control. Three to five mice per group were used in the preparation of the total RNAs, and qRT-PCR analyses was assayed in duplicate for each sample. The values of data represent the mean \pm SD. Asterisk symbol $(*)$ indicates significant $P<0.05$ compared to the No treated group. Sharp symbol (\#) indicates significant $P<0.05$ compared to the HFD + Vehicle treated group

inhibition of hepatic steatosis, since the activation of autophagy is considered a promising strategy to inhibit lipid accumulation in the liver [57]. Ginsenoside Rb2 partly activates the autophagic pathway through inhibition of the AMPK or SIRT1 pathway in $\mathrm{db} / \mathrm{db}$ mice [58]. Also, resveratrol and akebia saponin D prevent hepatic steatosis, accompanied with up-regulation of autophagy markers such as LC3-II, Beclin 1 and p62 [59, 60]. Similar effects on the induction of autophagy and prevention of hepatic steatosis have been reported in obesity animals and hepatic cell lines after exposure to the bergamot polyphenol fraction (BPF) and capsaicin $[29,60,61]$. It is also documented that induction of hepatic autophagy enhances the effects of quercetin, metformin and Eucommia ulmoides leaf extract [30, 62, 63]. In this study, hepatic autophagy is significantly activated with EMfC in the HFD-induced obesity model during anti-hepatic steatosis activity. The expression of autophagy marker proteins and PI3K/AKT/mTOR signaling pathway remarkably recover after exposure to EMfC. These results are consistent with previous studies, although further research on the mechanism of action is required. The results of the present study especially provide novel evidence that the anti-hepatic steatosis of EMfC may be associated with the amelioration of the induction step and late suppression step on the autophagic flux and autophagosomes formation, although HFD treatment also prevents these processes [57].

Among the several autophagy marker proteins, LC3-II is widely used as one of the autophagosome markers, since the amount of LC3-II reflects the number of autophagosomes and autophagy-related structures [57, 64]. LC3 is localized at the membranes and autophagosomes, and processed into LC3-I and LC3-II through the C-terminal cleavage of Atg4 and conjugation of phosphatidylethanolamine [65]. Especially, enhanced levels of LC3-II represent not only autophagy induction, but also a blockade in the autophagosome maturation [66]. Various animal models including ob/ob mice [60], the HFD-treated C57BL/6J mice [67] and HFD-treated Wistar rat [68] show increased levels of LC3-II during hepatic steatosis. A similar increase in the level of LC3II was observed in our current study using the HFDinduced obesity model, although the rate of enhancement was varied. These results indicate that LC3-II is a key marker for anti-hepatic steatosis induced by fermented natural products, including EMfC.

In this study, we investigated the role of EMfC on activation mechanism of autophagy during anti-hepatic steatosis. EMfC induced activation of autophagy via the $\mathrm{PI} 3 \mathrm{~K} / \mathrm{AKT} / \mathrm{mTOR}$ signaling pathway in the HFDinduced obesity model as shown Figs. 5 and 6. A similar 

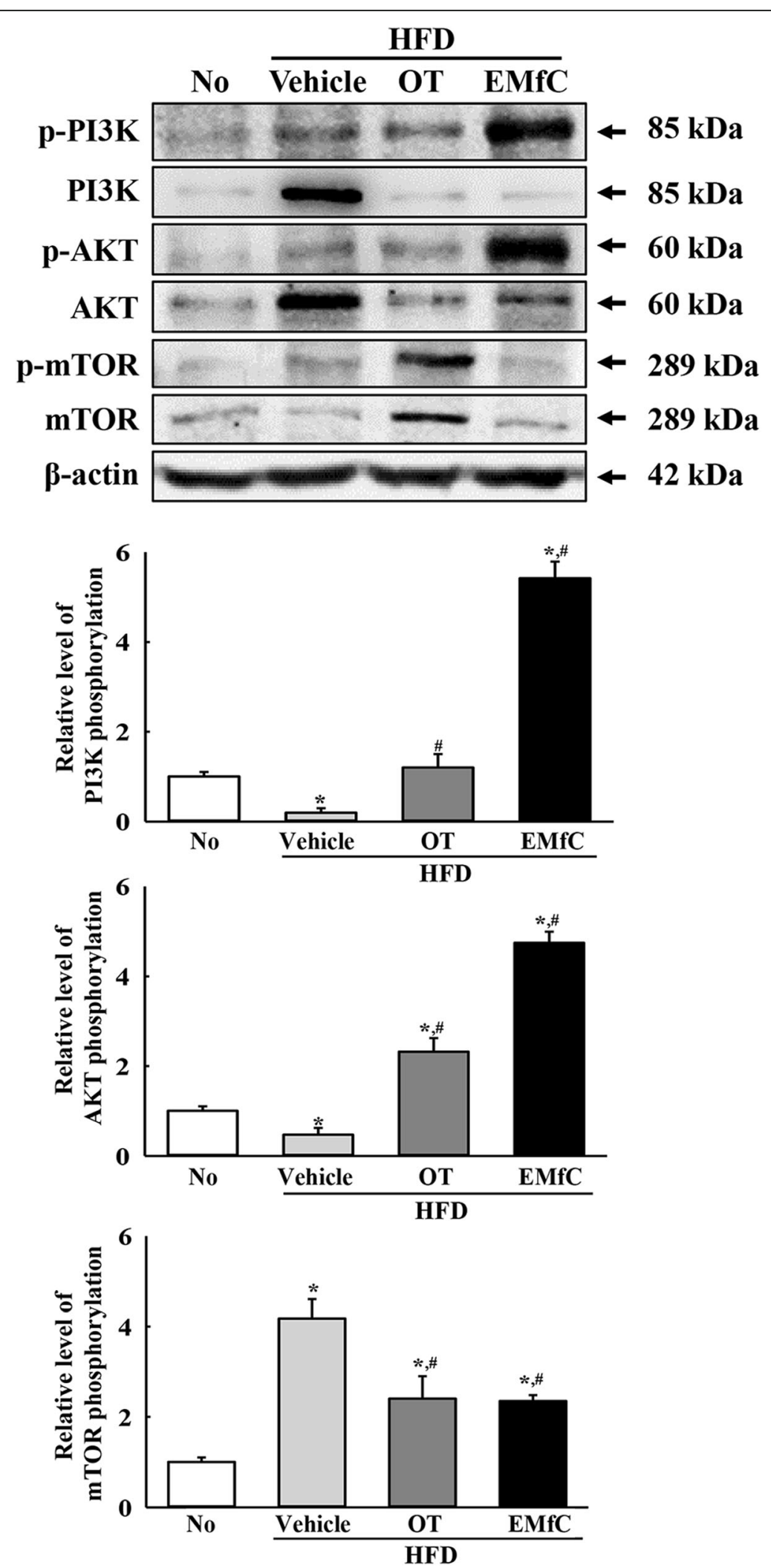

Fig. 5 (See legend on next page.) 
(See figure on previous page.)

Fig. 5 Expression of PI3K/AKT/mTOR signaling pathway in liver tissue. Western blot analysis measured the p-PI3K, PI3K, p-AKT, AKT, p-mTOR, mTOR and $\beta$-actin proteins in total liver homogenate using their specific antibodies. Band intensity of each protein were measured using an imaging densitometer, and the expressions of the six proteins were calculated relative to the intensity of $\beta$-actin protein. Three to five mice per group were used in the preparation of liver homogenates, and Western blot analysis was assayed in duplicate for each sample. Data represent the mean \pm SD. Asterisk symbol $\left(^{*}\right)$ indicates significant $P<0.05$ compared to the No treated group. Sharp symbol (\#) indicates significant $P<0.05$ compared to the HFD + Vehicle treated group

regulatory mechanism was observed after the treatment of several compounds with anti-obesity activity. Akebia saponin D (ASD) treatment prevent the oleic acid (OA)induced upregulation of LC3-II, Beclin and P62 expression as well as accumulation of lipid droplets in ob/ob mice [59]. Also, Lycium barbarum polysaccharides induced the down-regulation of p-mTOR and p62 level, while the expression level of Beclin and LC3 were enhanced in HFD-induced NASH rat model [69]. The decrease of pmTOR and p-AKT level was detected in dimethylnitrosamine (DMN)-induced hepatic fibrosis model after treatment of dioscin [70]. However, some differences were reported on the regulation of autophagy markers, key regulators of autophagy and signaling pathway in animal model treated with anti-obesity products although autophagy flux was activated. Several key regulators of autophagy including Beclin 1, ATG7, LAMP1 and LAMP2 were upregulated in HFD-fed C57BL/6J mice after astaxanthin treatment, while the phosphorylation level of Akt decreased in same group
[71]. Ginsenoside Rb2 induce the enhancement of LC3-II and decline of mTOR phosphorylation in $\mathrm{db} / \mathrm{db}$ mice [57]. Resveratrol prevent hepatic steatosis and increase the expression of LC3 proteins in HFD-fed Wistar rats [58]. Also, the increased level of LC3 and Beclin 1 protein was detected in cafeteria (CAF) diet-fed WIST rats treated with bergamot polyphenol fraction (BPF) during the reduce of hepatic steatosis and total lipid content [29]. Furthermore, EGCG treatment induce a similar effect on the regulation of autophagy such as activation of autophagy and upregulation of autophagic biomarkers [72]. Therefore, we thought that these differences can be attributed to variety in the composition of treated products, pathological severity of hepatic steatosis and treatment conditions between each study.

It is difficult to clearly verify the bioactive compound candidate responsible for the improvement effects of EMfC on the inflammatory response and autophagy regulation. However, several previous studies provided a clue for correlation between
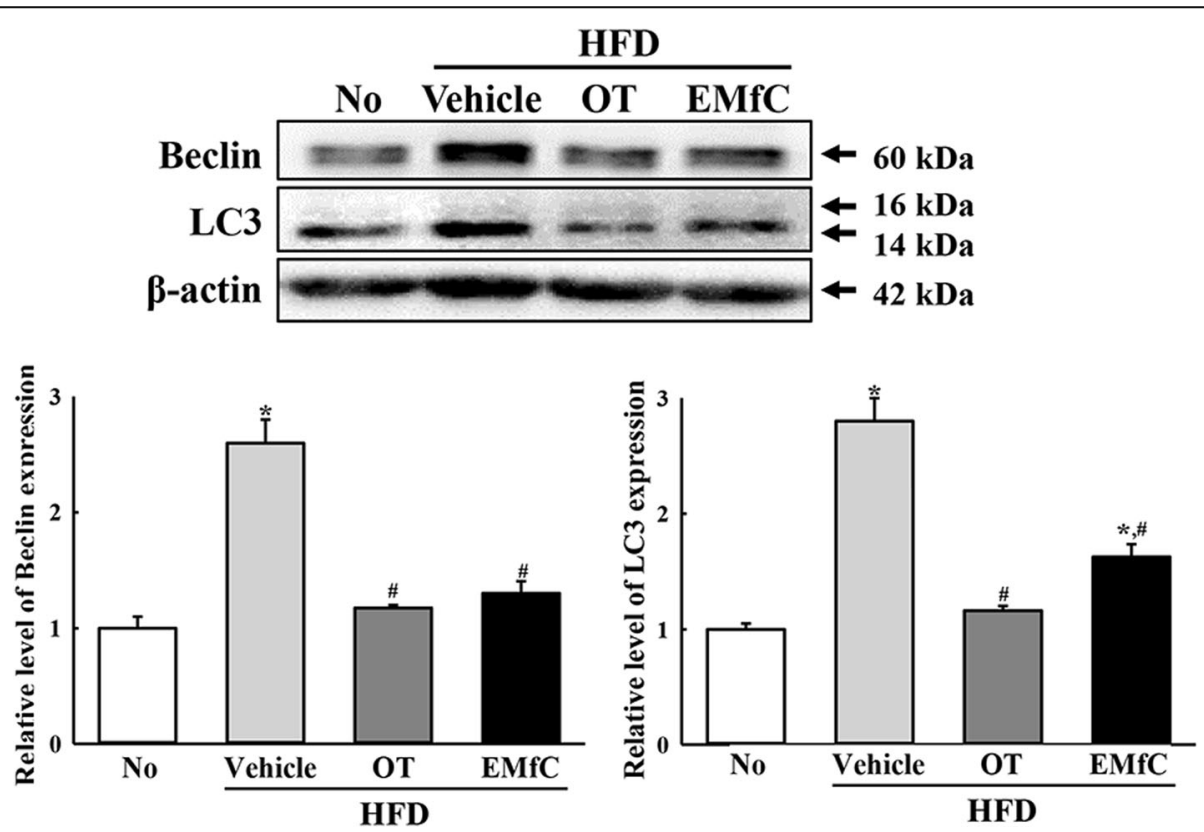

Fig. 6 Expression of autophagy regulators in liver tissue. Western blot analysis measured the Beclin, LC3-I/II and $\beta$-actin proteins in total liver homogenate using their specific antibodies. Band intensity of each protein were measured using an imaging densitometer, and the expressions of the two proteins were calculated relative to the intensity of $\beta$-actin protein. Three to five mice per group were used in the preparation of liver homogenates, and Western blot analysis was assayed in duplicate for each sample. Data represent the mean \pm SD. Asterisk symbol $(*)$ indicates significant $P<0.05$ compared to the No treated group. Sharp symbol (\#) indicates significant $P<0.05$ compared to the HFD + Vehicle treated group 

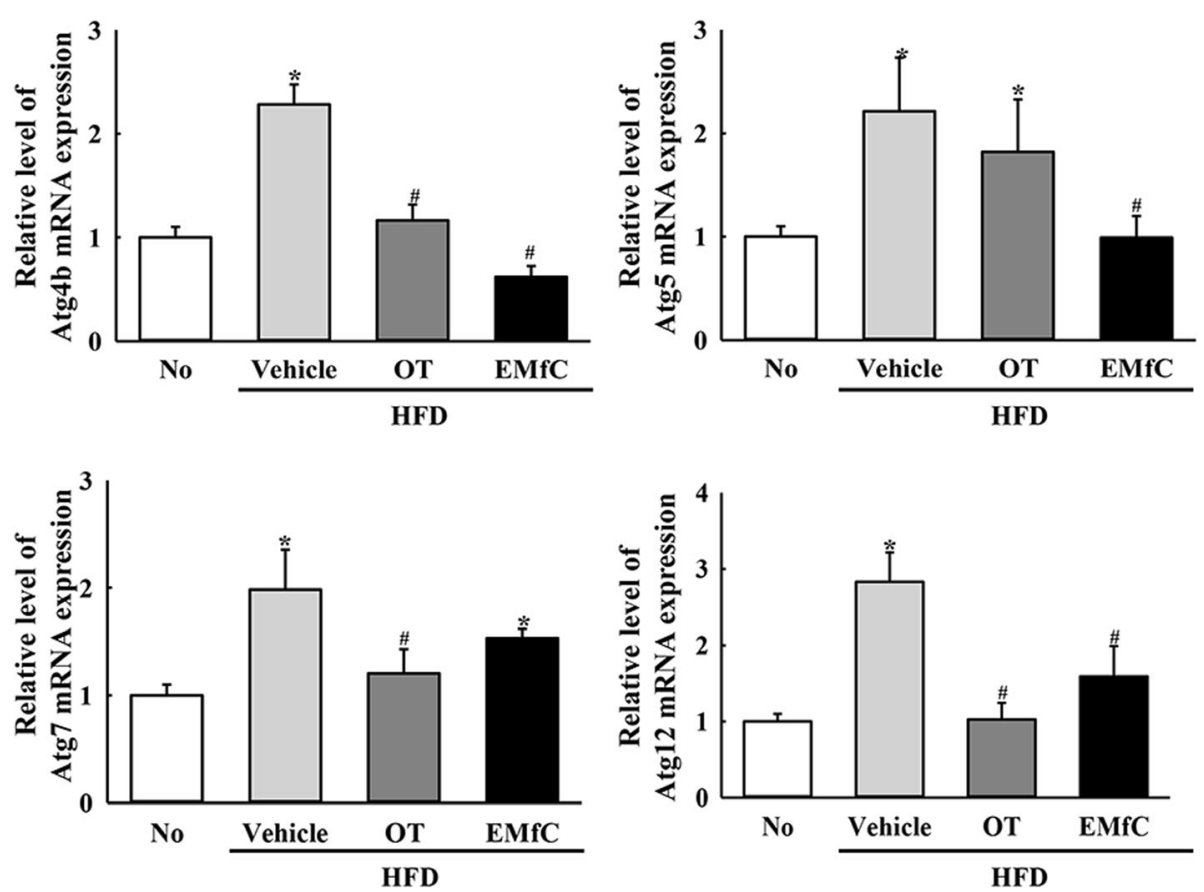

Fig. 7 Transcription of autophagy related genes in liver tissue. The levels of Atg4b, Atg5, Atg7, and Atg12 mRNA in the total transcripts of liver tissue were measured by qRT-PCR analyses using their specific primers. The relative levels of the Atg4b, Atg5, Atg7, and Atg12 mRNA were calculated based on the intensity of $\beta$-actin as an endogenous control. Three to five mice per group were used in the preparation of the total RNAs, and qRT-PCR analyses was assayed in duplicate for each sample. The values of data represent the mean \pm SD. Asterisk symbol $(*)$ indicates significant $P<0.05$ compared to the No treated group. Sharp symbol (\#) indicates significant $P<0.05$ compared to the HFD + Vehicle treated group

bioactive compounds and these effects. The first candidate is cordycepin because it show anti-obesity effects as well as multiple-biological effects including modulation of immune response, inhibition of tumor growth, hypotensive and vasorelaxation activities, and promoting secretion of adrenal hormone [73]. This compound was detected in the HPLC chromatogram of EMfC under the optimal conditions [33]. Also, other candidates are 4 compounds including mulberroside A, 5,7,2'trihydroxyflavanone-4'-O- $\beta$-d-glucoside, albanols $\mathrm{A}$ and albanols B in 70\% alcohol extract fractions of the Egyptian M. alba. They inhibited LDL atherogenic modifications and lipid peroxides formation in hypercholesterolemic rats [74]. In this study, we did not investigate what the bioactive compound in EMfC induce the anti-hepatic steatosis through the regulation of the inflammatory response and autophagy pathway. However, the previous study of our team provided few evidences that cordycepin has been considered as key compound for these effects although further research will be needed.

Generally, oxidative balance impairment, NAFLD-related fat accumulation and mitochondrial dysfunction have been considered as one of major target for preventing the progression of hepatic steatosis in various studies [75]. During fat accumulation in hepatocytes, ROS production and lipid peroxidation were excessively enhanced, and subsequently lead to the formation of other reactive metabolites including 4-HNE and MDA [76, 77]. Therefore, several fermented products with high antioxidant activity such as fermented green tea extracts and garlic extract improved and prevent hepatic steatosis of HFD-induced model [78, 79]. However, in this study, we did not investigate about oxidative stress and free radical scavenging activity of EMfC in liver tissue of HFD-induced obesity model because this extract showed a relatively low level of DPPH scavenging activity $\left(\mathrm{IC}_{50}=579 \mu \mathrm{g} / \mathrm{mL}\right)$ in preliminary study (Data not shown). Instead, we focused on the improvement effect and action mechanism of EMfC in the inflammation and autophagy although further analysis for detail mechanism such as inflammasome is required.

Meanwhile, various animal models such as ob/ob mice and Zucker ( $\mathrm{fa} / \mathrm{fa}$ ) rats have been used to study the pathogenesis and therapeutic drugs for obesity and diabetes although they did not completely reflect human diseases [80]. These model for obesity can classified into mutation type being based on mutation or manipulation of individual genes and genetically intact type exposing obesogenic environment such as HFD [81]. Among these, HFD-induced obesity model was firstly reported as obesogenic environmentinduced model in 1959 [82]. They showed the reduction of insulin and leptin sensitivity, alteration of 


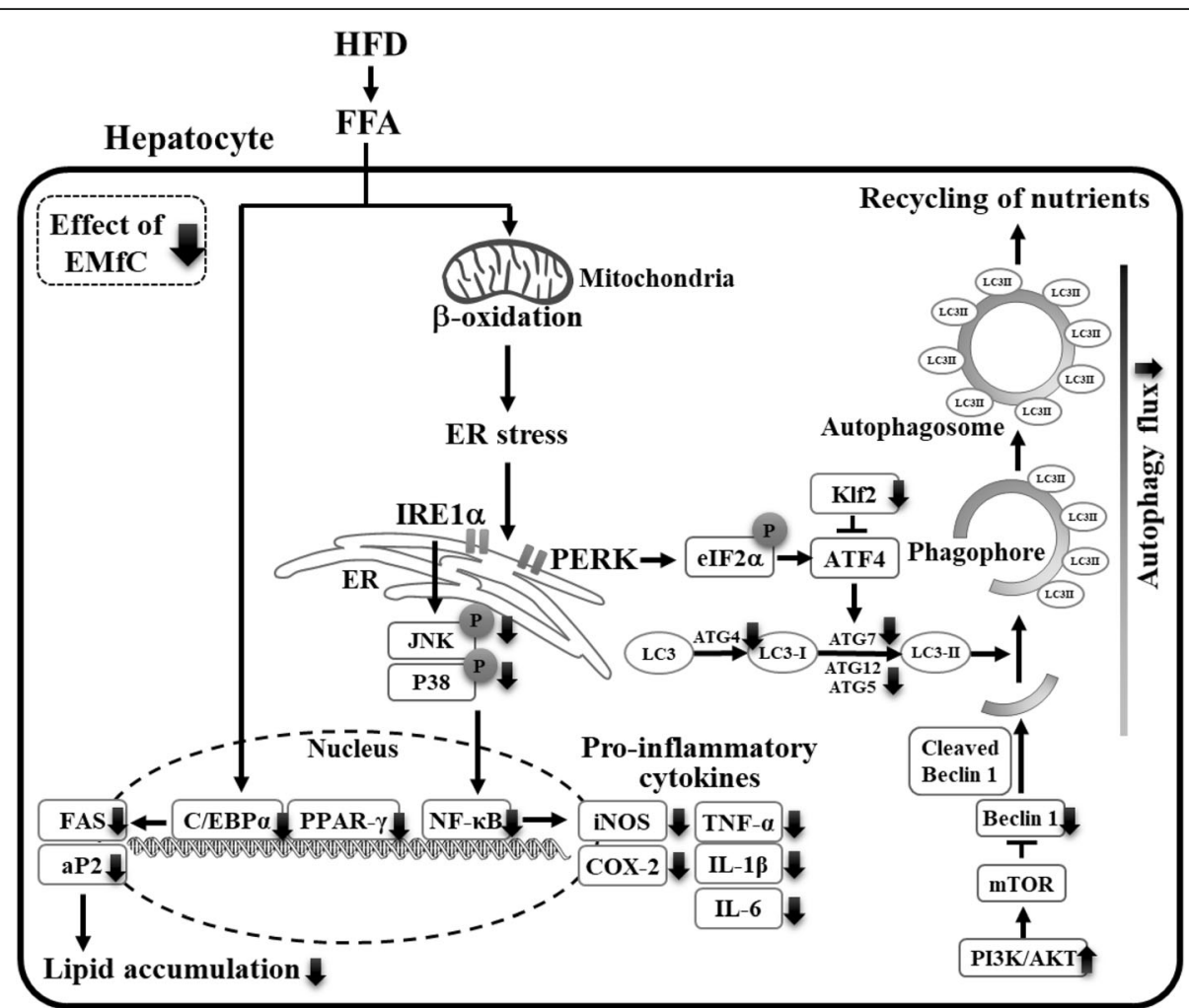

Fig. 8 Proposed mechanism of EMfC action in amelioration of inflammatory response and autophagy pathway during anti-hepatic steatosis in HFD-induced obesity mice. In this scheme, the anti-hepatic steatosis effects of EMfC are thought to be exerted the suppression of inflammatory response and autophagy flux in hepatocytes during HFD-induced $\beta$-oxidation

neuropeptide expression, hyperglycemia and compromised $\beta$-cell function [83-85]. Especially, HFD treatment for 12 weeks induce some significant alterations on the pathology and biochemical markers for hepatic steatosis. In the liver tissue of above mice, adipocyte size, percentage of crown-like structures, severity of hepatic steatosis, and number of inflammatory foci were remarkably increased compared with normal diet (ND)-fed mice. A similar enhancement was detected on the levels of serum biochemical markers including TC, glucose, and aminotransferases (AST and ALT) in HFD treated mice for 12 weeks [32, 86-88]. Also, the increase of insulin and leptin concentration were detected in the same mice [89]. Base on above reports, 12-week period had been selected as the optimum period for inducing hepatic steatosis of C57BL/6N mice in this study. However, HFD-induced model provides limited information because only one high fat formula employed to induce obesity. The treatment of diet based on saturated fatty acids exhibit the typical phenotypes of HFD-induced obesity, while the treatment of diet containing polyunsaturated $\omega-3$ fatty acid show some beneficial effects on the body position and insulin action [90]. Therefore, more studies are necessary to clarify the influence of the specific fat composition in HFD-induced obesity model.

\section{Conclusions}

In conclusion, the current study demonstrates that EMfC exerts anti-hepatic steatosis activity by successfully reducing the inflammatory response, including mast cell infiltration, inflammatory mediators and cytokines, in the liver tissue of HFD-induced obese mice. In addition, the anti-inflammatory response of EMfC is mediated by autophagy flux, PI3K/AKT/mTOR signaling pathway and autophagic gene transcripts. The regulatory effects of EMfC on the inflammatory response and autophagy during the suppression of hepatic steatosis indicates the potential of EMfC as an anti-obesity drug that results in lipolysis (Fig. 8).

\section{Supplementary information}

Supplementary information accompanies this paper at https://doi.org/10. 1186/s12906-020-03076-2.

\section{Additional file 1.}

Additional file 2. 


\section{Abbreviations}

AKT: Protein kinase B; Atg: Autophagy-related gene; COX: Cyclooxygenase; EMfC: Extract of mulberry leaves fermented with Cordyceps militaris; ERK: Extracellular signal-regulated kinase; HFD: High fat diet; IL: Interleukin; iNOS: Inducible nitric oxide synthase; JNK: c-Jun N-terminal kinases; KIf2: Krüppel-like Factor 2; LC3: Light chain 3; MAPK: Mitogen-activated protein kinase; mTOR: Mammalian target of rapamycin; NF-KB: Nuclear Factor-kappaB; OT: Orlistat; PI3K: Phosphoinositide 3-kinase; TNF-a: Tumor necrosis factor-a

\section{Acknowledgements}

We thank Jin Hyang Hwang, the animal technician, for directing the care and management of animals of at the Laboratory Animal Resources Center in Pusan National University.

\section{Authors' contributions}

M.R.L.: Formal analysis, Investigation and Visualization; J.E.K: Formal analysis; J.W.P: Formal analysis; M.J.K: Formal analysis; H.J.C: Investigation; S.J.B: Investigation; K.M.K: Data curation; Y.W.C.: Data curation, Writing-review and editing; J.T.H: Writing-review and editing; D.Y.H.: Conceptualization, Methodology, Investigation, Writing-original draft preparation, Project administrator, Supervision and Funding acquisition. This manuscript has been approved by all listed authors, no permission is needed.

\section{Funding}

This research was supported by grants to Dr. Dae Youn Hwang from the Korea Institute of Planning Evaluation for Technology of Food, Agriculture, Forestry and Fisheries (116027-032-HD030). The funders had no role in study design, data collection and analysis, decision to publish, or preparation of the manuscript.

\section{Availability of data and materials}

The extract of mulberry leaves fermented with Cordyceps militaris (EMfC) used in this study are available from the corresponding author on reasonable request.

\section{Ethics approval and consent to participate}

The Pusan National University Animal Ethics Committee (no. PNU-2017-1519) approved the protocol for the present study.

\section{Consent for publication}

Not applicable.

\section{Competing interests}

The authors declare that they have no competing interests. Dae Youn Hwang, the corresponding author, is a member of the editorial board for [BMC Complementary and Alternative Medicine], which is on a voluntary basis and has no competing interests. All authors alone are responsible for the content and writing of the paper.

\section{Author details}

${ }^{1}$ Department of Biomaterials Science, College of Natural Resources \& Life Science/Life and Industry Convergence Research Institute, Pusan National University, Miryang 50463, South Korea. ${ }^{2}$ Department of Horticultural Bioscience, College of Natural Resources \& Life Science/Life and Industry Convergence Research Institue, Pusan National University, Miryang 50463, South Korea. ${ }^{3}$ Life Science Research Institute, Novarex Co., Ltd, Chungju 28126, South Korea. ${ }^{4}$ College of Pharmacy, Chungbuk National University, Chungju 28644, South Korea.

Received: 13 December 2019 Accepted: 8 September 2020 Published online: 18 September 2020

\section{References}

1. Monteiro R, Azevedo I. Chronic inflammation in obesity and the metabolic syndrome. Mediat Inflamm. 2010;2010:289645. https://doi.org/10.1155/2010/ 289645

2. Qatanani M, Lazar MA. Mechanisms of obesity-associated insulin resistance: many choices on the menu. Genes Dev. 2007;21:1443-55. https://doi.org/10. 1101/gad.1550907.
3. Solinas G, Karin M. JNK1 and IKKß: molecular links between obesity and metabolic dysfunction. FASEB J. 2010;24(8):2596-611. https://doi.org/10. 1096/fj.09-151340

4. Sun B, Karin M. Obesity, inflammation, and liver cancer. J Hepatol. 2012; 56(3):704-13. https://doi.org/10.1016/j.jhep.2011.09.020.

5. Solinas G, Naugler W, Galimi F, Lee MS, Karin M. Saturated fatty acids inhibit induction of insulin gene transcription by JNK-mediated phosphorylation of insulin-receptor substrates. Proc Natl Acad Sci U S A. 2006;103(44):16454-9. https://doi.org/10.1073/pnas.0607626103.

6. Solinas G, Vilcu C, Neels JG, Bandyopadhyay GK, Luo JL, Naugler W, Grivennikov S, Wynshaw-Boris A, Scadeng M, Olefsky JM, Karin M. JNK1 in hematopoietically derived cells contributes to diet-induced inflammation and insulin resistance without affecting obesity. Cell Metab. 2007;6(5):38697. https://doi.org/10.1016/j.cmet.2007.09.011.

7. Fu S, Watkins SM, Hotamisligil GS. The role of endoplasmic reticulum in hepatic lipid homeostasis and stress signaling. Cell Metab. 2012;15:623-34. https://doi.org/10.1016/j.cmet.2012.03.007.

8. Ganley IG, Wong PM, Gammoh N, Jiang X. Distinct autophagosomallysosomal fusion mechanism revealed by thapsigargin-induced autophagy arrest. Mol Cell. 2011;42:731-43. https://doi.org/10.1016/j.molcel.2011.04.024.

9. Hirose S, Asano K, Nakane A. Attenuation of obesity-induced inflammation in mice orally administered with salmon cartilage proteoglycan, a prophylactic agent. Biochem Biophys Res Commun. 2017;484(3):480-5. https://doi.org/10.1016/j.bbrc.2017.01.056.

10. Choi JH, Jin SW, Choi CY, Kim HG, Kim SJ, Lee HS, Chung YC, Kim EJ, Lee YC, Jeong HG. Saponins from the roots of Platycodon grandiflorum ameliorate high fat diet-induced non-alcoholic steatohepatitis. Biomed Pharmacother. 2017:86:205-12. https://doi.org/10.1016/j.biopha.2016.11.107.

11. Kim H, Park M, Shin JH, Kwon O. Ethanolic extract of Acanthopanax koreanum Nakai alleviates alcoholic liver damage combined with a high-fat diet in C57BL/6J mice. Molecules. 2016;21(6):E681. https://doi.org/10.3390/ molecules21060681.

12. Xu N, Chu J, Wang M, Chen L, Zhang L, Xie Z, Zhang J, Ho CT, Li D, Wan X. Large yellow tea attenuates macrophage-related chronic inflammation and metabolic syndrome in high-fat diet treated mice. J Agric Food Chem. 2018, 66(15):3823-32. https://doi.org/10.1021/acs.jafc.8b00138.

13. Muthu PR, Bobby Z, Sankar P, Vickneshwaran V, Jacob SE. Amla (Emblica officinalis) improves hepatic and renal oxidative stress and the inflammatory response in hypothyroid female wistar rats fed with a high-fat diet. J Basic Clin Physiol Pharmacol. 2018;29(2):175-84. https://doi.org/10.1515/jbcpp2017-0116.

14. Joung H, Kim B, Park H, Lee K, Kim HH, Sim HC, Do HJ, Hyun CK, Do MS Fermented Moringa oleifera decreases hepatic adiposity and ameliorates glucose intolerance in high-fat diet-induced obese mice. J Med Food. 2017; 20(5):439-47. https://doi.org/10.1089/jmf.2016.3860.

15. Foster MT, Gentile CL, Cox-York K, Wei Y, Wang D, Estrada AL, Reese L, Mille T, Pagliassotti MJ, Weir TL. Fuzhuan tea consumption imparts hepatoprotective effects and alters intestinal microbiota in high saturated fat diet-fed rats. Mol Nutr Food Res. 2016;60(5):1213-20. https://doi.org/10. 1002/mnfr.201500654.

16. Choi J, Kwon SH, Park KY, Yu BP, Kim ND, Jung JH, Chung HY. The antiinflammatory action of fermented soybean products in kidney of high-fat-fed rats. J Med Food. 2011;14(3):232-9. https://doi.org/10.1089/jmf.2010.1039.

17. Angulo P. Nonalcoholic fatty liver disease. N Engl J Med. 2002;346(16):122131. https://doi.org/10.1056/NEJMra011775.

18. Ludwig J, Viggiano TR, McGill DB, Oh BJ. Nonalcoholic steatohepatitis: Mayo Clinic experiences with a hitherto unnamed disease. Mayo Clin Proc. 1980; 55(7):434-8.

19. Browning JD, Horton JD. Molecular mediators of hepatic steatosis and liver injury. J Clin Investig. 2004;114(2):147-52. https://doi.org/10.1172/JCI22422.

20. Laurin J, Lindor KD, Crippin JS, Gossard A, Gores GJ, Ludwig J, Rakela J, McGill DB. Ursodeoxycholic acid or clofibrate in the treatment of nonalcohol-induced steatohepatitis: a pilot study. Hepatology. 1996;23(6):14647. https://doi.org/10.1002/hep.510230624.

21. Lavine JE. Vitamin E treatment of nonalcoholic steatohepatitis in children: a pilot study. J Pediatr. 2000;136(6):734-8.

22. Abdelmalek MF, Angulo P, Jorgensen RA, Sylvestre PB, Lindor KD. Betaine, a promising new agent for patients with nonalcoholic steatohepatitis: results of a pilot study. Am J Gastroenterol. 2001;96(9):2711-7.

23. Caldwell SH, Hespenheide EE, Redick JA, lezzoni JC, Battle EH, Sheppard BL. A pilot study of a thiazolidinedione, troglitazone, in nonalcoholic 
steatohepatitis. Am J Gastroenterol. 2001;96(2):519-25. https://doi.org/10. 1111/j.1572-0241.2001.03553.x

24. Arioglu E, Duncan-Morin J, Sebring N, Rother Kl, Gottlieb N, Lieberman J, Herion D, Kleiner DE, Reynolds J, Premkumar A, Summer AE, Hoofnagle J, Reitman M, Taylor SI. Efficacy and safety of troglitazone in the treatment of lipodystrophy syndromes. Ann Intern Med. 2000;133(4):263-74. https://doi. org/10.7326/0003-4819-133-4-200008150-00009.

25. Saibara T, Onishi S, Ogawa Y, Yoshida S, Enzan H. Bezafibrate for tamoxifeninduced non-alcoholic steatohepatitis. Lancet. 1999;353(9166):1802. https:// doi.org/10.1016/S0140-6736(05)75907-9.

26. Wong WW, Wong GL, Chan AW, Chu WC, Choi PC, Chim AM, Yiu KK, Yu J, Chan FK, Chan HL. Treatment of non-alcoholic steatohepatitis with Phyllanthus urinaria: a randomized trial. J Gastroenterol Hepatol. 2013;28(1): 57-62. https://doi.org/10.1111/j.1440-1746.2012.07286.x.

27. Daneshi-Maskooni M, Keshavarz SA, Mansouri S, Qorbani M, Alavian SM, Badri-Fariman M, Jazayeri-Tehrani SA, Sotoudeh G. The effects of green cardamom on blood glucose indices, lipids, inflammatory factors, paraxonase-1, sirtuin-1, and irisin in patients with nonalcoholic fatty liver disease and obesity: study protocol for a randomized controlled trial. Trials. 2017;18(1):260. https://doi.org/10.1186/s13063-017-1979-3.

28. Haga S, YiMin YH, Jin S, Sogon T, Morita N, Ozaki M. Extracts of bilberry (Vaccinium myrtillus L.) fruits improve liver steatosis and injury in mice by preventing lipid accumulation and cell death. Biosci Biotechnol Biochem. 2019;83(11):2110-20. https://doi.org/10.1080/09168451.2019.1634514.

29. Parafati M, Lascala A, Morittu VM, Trimboli F, Rizzuto A, Brunelli E, Coscarelli F, Costa N, Britti D, Ehrlich J, Isidoro C, Mollace V, Janda E. Bergamot polyphenol fraction prevents nonalcoholic fatty liver disease via stimulation of lipophagy in cafeteria diet-induced rat model of metabolic syndrome. J Nutr Biochem. 2015;26:938-48. https://doi.org/10.1016/j.jnutbio.2015.03.008.

30. Liu L, Gao C, Yao P, Gong Z. Quercetin alleviates high-fat diet-induced oxidized lowdensity lipoprotein accumulation in the liver: implication for autophagy regulation. Biomed Res Int. 2015;2015:607531. https://doi.org/10.1155/2015/607531.

31. Li Z, Zemin Y, Guang J. Herbal extracts and natural products in alleviating non-alcoholic fatty liver disease via activating autophagy. Front Pharmacol. 2018;9:1459. https://doi.org/10.3389/fphar.2018.01459.

32. Lee MR, Kim JE, Choi JY, Park JJ, Kim HR, Song BR, Choi YW, Kim KM, Song HK, Hwang DY. Anti-obesity effect in high-fat-diet-induced obese C57BL/6 mice: study of a novel extract from mulberry (Morus alba) leaves fermented with Cordyceps militaris. Exp The Med. 2019;17(3):2185-93. https://doi.org/10 3892/etm.2019.7191.

33. Lee MR, Kim JE, Yun WB, Choi JY, Park JJ, Kim HR, Song BR, Choi YW, Kim KM, Hwang DY. Lipolytic effect of novel extracts from mulberry (Morus alba) leaves fermented with Cordyceps militaris in the primary adipocytes derived from SD rats. Lab Anim Res. 2017;33:270-9. https://doi.org/10.5625/lar.2017. 33.3.270.

34. Lee MR, Bae SJ, Kim JE, Song BR, Choi JY, Park JJ, Park JW, Kang MJ, Choi HJ, Choi YW, Kim KM, Hwang DY. Inhibition of endoplasmic reticulum stress in high-fat-diet-induced obese C57BL/6 mice: efficacy of a novel extract from mulberry (Morus alba) leaves fermented with Cordyceps militaris. Lab Anim Res. 2018;34(4):288-94. https://doi.org/10.5625/lar.2018.34.4.288.

35. Brayton CF. Dimethyl sulfoxide (DMSO): a review. Cornell Vet. 1986;76(1):61-90.

36. Ann JY, Eo HY, Lim YS. Mulberry leaves (Morus alba L.) ameliorate obesityinduced hepatic lipogenesis, fibrosis, and oxidative stress in high-fat diet-fed mice. Genes Nutr. 2015;10:46. https://doi.org/10.1007/s12263-015-0495-.

37. Hwang JT, Shin EJ, Chung MY, Park JH, Chung SW, Choi HK. Ethanol extract of Allium fistulosum inhibits development of non-alcoholic fatty liver disease. Nutr Res Pract. 2018;12(2):110-7. https://doi.org/10.4162/nrp.2018.12.2.110.

38. Kleiner DE, Brunt EM, Van Natta M, Behling C, Contos MJ, Cummings OW, Ferrell LD, Liu YC, Torbenson MS, Unalp-Arida A, Yeh M, McCullough AJ, Sanyal AJ, Nonalcoholic Steatohepatitis Clinical Research Network. Design and validation of a histological scoring system for nonalcoholic fatty liver disease. Hepatology. 2005;41(6):1313-21. https://doi.org/10.1002/hep.20701.

39. Kwak MH, Kim JE, Go J, Son HJ, Lee HS, Hong JT, Hwang DY. Effects of aqueous extract from red Liriope platyphylla on phthalic-anhydride-induced atopic dermatitis in Interleukin-4/luciferase/consensus non-coding sequence-1 transgenic mice evaluated in terms of luciferase signal and general phenotype biomarkers. J Trad Chinese Med. 2017;37(4):475-85. https://doi.org/10.1016/S0254-6272(17)30154-1.

40. Livak KJ, Schmittgen TD. Analysis of relative gene expression data using real-time quantitative PCR and the 2(- $\triangle \triangle C(T))$ method. Methods. 2001;25(4): 402-8. https://doi.org/10.1006/meth.2001.1262.
41. Kobayashi Y, Miyazawa M, Kamei A, Abe K, Kojima T. Ameliorative effects of mulberry (Morus alba L.) leaves on hyperlipidemia in rats fed a high-fat diet induction of fatty acid oxidation, inhibition of lipogenesis, and suppression of oxidative stress. Biosci Biotechnol Biochem. 2010;74:2385-95. https://doi. org/10.1271/bbb.100392.

42. Sugimoto $M$, Arai $H$, Taura $Y$, Murayama T, Khaengkhan $P$, Nishio T, Ono K, Ariyasu H, Akamizu T, Ueda Y, Kita T, Harada S, Kamei K, Yokode M. Mulberry leaf ameliorates the expression profile of adipocytokines by inhibiting oxidative stress in white adipose tissue in $\mathrm{db} / \mathrm{db}$ mice. Atherosclerosis. 2009; 204(2):388-94. https://doi.org/10.1016/j.atherosclerosis.2008.10.021.

43. Van Gaal LF, Broom JI, Enzi G, Toplak H. Efficacy and tolerability of orlistat in the treatment of obesity: a 6-month dose-ranging study. Eur J Clin Pharmacol. 1998;54:125-32. https://doi.org/10.1007/s002280050433.

44. Miles JM, Leiter L, Hollander P, Wadden T, Anderson JW, Doyle M, Foreyt J, Aronne L, Klein S. Effects of orlistat in overweight and obese patients with type 2 diabetes treated with metformin. Diabetes Care. 2002;25:1123-8. https://doi.org/10.2337/diacare.25.7.1123.

45. Gokcel A, Gumurdulu Y, Karakose H, Ertorer EM, Tanaci N, Tutuncu NB, Guvener N. Evaluation of the safety and efficacy of sibutramine, orlistat and metformin in the treatment of obesity. Diabetes Obes Metab. 2002;4:49-55. https://doi.org/10.1046/j.1463-1326.2002.00181.x.

46. Gillies CL, Abrams KR, Lambert PC, Cooper NJ, Sutton AJ, Hsu RT, Khunti K. Pharmacological and lifestyle interventions to prevent or delay type 2 diabetes in people with impaired glucose tolerance: systematic review and meta-analysis. BMJ. 2007;334(7588):299. https://doi.org/10.1136/bmj.39063. 689375.55.

47. McDuffie JR, Calis KA, Uwaifo Gl, Sebring NG, Fallon EM, Hubbard VS, Yanovski JA. Three-month tolerability of orlistat in adolescents with obesityrelated comorbid conditions. Obes Res. 2002;10:642-50. https://doi.org/10. 1038/oby.2002.87.

48. Heck AM, Yanovski JA, Calis KA. Orlistat, a new lipase inhibitor for the management of obesity. Pharmacotherapy. 2000;20(3):270-9. https://doi. org/10.1592/phco.20.4.270.34882.

49. Guerciolini R. Mode of action of orlistat. Int J Obes Relat Metab Disord. 1997;21(Suppl 3):S12-23 http://europepmc.org/article/med/9225172.

50. Unluhizarcı K, Kelestimur F, Sahin Y, Bayram F. The treatment of insulin resistance does not improve adrenal cytochrome P450c17a enzyme dysregulation in polycystic ovary syndrome. Eur J Endocrinol. 1999;140:5661. https://doi.org/10.1530/eje.0.1400056.

51. Diamanti-Kandarakis E, Kouli C, Tsianeteli T, Bergiele A. Therapeutic effects of metformin on insulin resistance and hyperandrogenism in polycystic ovary syndrome. Eur J Endocrinol. 1998;138:269-74. https://doi.org/10.1530/eje.0. 1380269.

52. Velazquez EM, Mendoza S, Hamer T, Sosa F, Glueck CJ. Metformin therapy in polycystic ovary syndrome reduces hyperinsulinemia, insulin resistance, hyperandrogenemia, and systolic blood pressure while facilitating normal menses and pregnancy. Metabolism. 1994;43:647-54. https://doi.org/10. 1016/0026-0495(94)90209-7.

53. Jarrar MH, Baranova A, Collantes R, Ranard B, Stepanova M, Bennett C, Fang Y, Elariny H, Goodman Z, Chandhoke V, Younossi ZM. Adipokines and cytokines in non-alcoholic fatty liver disease. Aliment Pharmacol Ther. 2008; 27(5):412-21. https://doi.org/10.1111/j.1365-2036.2007.03586.x.

54. Weinhold B, Rüther U. Interleukin-6-dependent and -independent regulation of the human C-reactive protein gene. Biochem J. 1997;327(2): 425-9. https://doi.org/10.1016/j.molimm.2007.12.017.

55. Visser M, Bouter LM, McQuillan GM, Wener MH, Harris TB. Elevated Creactive protein levels in overweight and obese adults. JAMA. 1999;282(22): 2131-5. https://doi.org/10.1001/jama.282.22.2131.

56. Zhang XJ, Chen S, Huang KX, Le WD. Why should autophagic flux be assessed? Acta Pharmacol Sin. 2013;34(5):595-9. https://doi.org/10.1038/aps. 2012.184 .

57. Huang Q, Wang T, Yang L, Wang HY. Ginsenoside Rb2 alleviates hepatic lipid accumulation by restoring autophagy via induction of Sirt1 and activation of AMPK. Int J Mol Sci. 2017;18(5):E1063. https://doi.org/10.3390/ ijms18051063.

58. Ding S, Jiang J, Zhang G, Bu Y, Zhang G, Zhao X. Resveratrol and caloric restriction prevent hepatic steatosis by regulating SIRT1-autophagy pathway and alleviating endoplasmic reticulum stress in high-fat diet-fed rats. PLOS One. 2017;12:e0183541. https://doi.org/10.1371/journal.pone.0183541.

59. Gong LL, Li GR, Zhang W, Liu H, Lv YL, Han FF, Wan ZR, Shi MB, Liu LH. Akebia saponin $D$ decreases hepatic steatosis through autophagy 
modulation. J Pharmacol Exp Ther. 2016;359:392-400. https://doi.org/10. 1124/jpet.116.236562.

60. Li Q, Li L, Wang F, Chen J, Zhao Y, Wang P, Nillus B, Liu D, Zhu Z. Dietary capsaicin prevents nonalcoholic fatty liver disease through transient receptor potential vanilloid 1-mediated peroxisome proliferator-activated receptor $\delta$ activation. Pflugers Arch. 2019:465(9):1303-16. https://doi.org/10. 1007/s00424-013-1274-4.

61. Li M, Sharma A, Yin C, Tan X, Xiao Y. Metformin ameliorates hepatic steatosis and improves the induction of autophagy in HFD-induced obese mice. Mol Med Rep. 2017;16(1):680-6. https://doi.org/10.3892/mmr.2017. 6637.

62. Lee GH, Lee HY, Park SA, Shin TS, Chae HJ. Eucommia ulmoides leaf extract ameliorates steatosis induced by high-fat diet in rats by increasing lysosomal function. Nutrients. 2019;11(2):E426. https://doi.org/10.3390/ nu11020426.

63. Yoshii SR, Mizushima N. Monitoring and measuring autophagy. Int J Mol Sci. 2017;18(9):E1865. https://doi.org/10.3390/ijms18091865.

64. Kabeya Y, Mizushima N, Ueno T, Yamamoto A, Kirisako T, Noda T, Kominami E, Ohsumi Y, Yoshimori T. LC3, a mammalian homologue of yeast Apg8p, is localized in autophagosome membranes after processing. EMBO J. 2000; 19(21):5720-8. https://doi.org/10.1093/emboj/19.21.5720.

65. Fass E, Shvets E, Degani I, Hirschberg K, Elazar Z. Microtubules support production of starvation-induced autophagosomes but not their targeting and fusion with lysosomes. J Biol Chem. 2006;281(47):36303-16. https://doi. org/10.1074/jbc.M607031200.

66. Mei S, Ni HM, Manley S, Bockus A, Kassel KM, Luyendyk JP, Copple BL, Ding WX. Differential roles of unsaturated and saturated fatty acids on autophagy and apoptosis in hepatocytes. J Pharmaco Exp Ther. 2011;339(2):487-98. https://doi.org/10.1124/jpet.111.184341.

67. Papackova Z, Dankova H, Palenickova E, Kazdova L, Cahova M. Effect of short- and long-term high-fat feeding on autophagy flux and lysosomal activity in rat liver. Physiol Res. 2012;61(2):S67-76 https://pubmed.ncbi.nIm. nih.gov/23130905/.

68. Buettner R, Parhofer KG, Woenckhaus M, Wrede CE, Kunz-Schughart LA, Schölmerich J, Bollheimer LC. Defining high-fat-diet rat models: metabolic and molecular effects of different fat types. J Mol Endocrinol. 2006;36(3): 485-501. https://doi.org/10.1677/jme.1.01909.

69. Xiao J, Xing F, Huo J, Fung ML, Liong EC, Ching YP, Xu A, Chang RC, So KF, Tipoe GL. Lycium barbarum polysaccharides therapeutically improve hepatic functions in non-alcoholic steatohepatitis rats and cellular steatosis model. Sci Rep. 2014;4:5587. https://doi.org/10.1038/srep05587.

70. Xu L, Yin L, Tao X, Qi Y, Han X, Xu Y, Song S, Li L, Sun P, Peng J. Dioscin, a potent ITGA5 inhibitor, reduces the synthesis of collagen against liver fibrosis: insights from SILAC-based proteomics analysis. Food Chem Toxicol. 2017;107(Pt A):318-28. https://doi.org/10.1016/j.fct.2017.07.014.

71. Jia Y, Wu C, Kim J, Kim B, Lee SJ. Astaxanthin reduces hepatic lipid accumulations in high-fat-fed (57BL/6J mice via activation of peroxisome proliferator-activated receptor (PPAR) alpha and inhibition of PPAR gamma and Akt. J Nutr Biochem. 2016;28:9-18. https://doi.org/10.1016/j.jnutbio. 2015.09.015.

72. Kim SN, Kwon HJ, Akindehin S, Jeong HW, Lee YH. Effects of epigallocatechin-3-Gallate on autophagic lipolysis in adipocytes. Nutrients. 2017:9(7):680. https://doi.org/10.3390/nu9070680.

73. Gao J, Lian ZQ, Zhu P, Zhu HB. Lipid-lowering effect of cordycepin (3'deoxyadenosine) from Cordyceps militaris on hyperlipidemic hamsters and rats. Yao Xue Xue Bao. 2011;46(6):669-76. https://pubmed.ncbi.nlm.nih. gov/21882527/.

74. El-Beshbishy HA, Singab AN, Sinkkonen J, Pihlaja K. Hypolipidemic and antioxidant effects of Morus alba L. (Egyptian mulberry) root bark fractions supplementation in cholesterol-fed rats. Life Sci. 2006;78(23):2724-33. https://doi.org/10.1016/j.lfs.2005.10.010.

75. Ferramosca A, Di Giacomo M, Zara V. Antioxidant dietary approach in treatment of fatty liver: new insights and updates. World J Gastroenterol. 2017;23(23):4146-57. https://doi.org/10.3748/wjg.v23.i23.4146.

76. Videla LA, Rodrigo R, Araya J, Poniachik J. Insulin resistance and oxidative stress interdependency in non-alcoholic fatty liver disease. Trends Mol Med. 2006;12(12):555-8. https://doi.org/10.1016/j.molmed.2006.10.001.

77. Araya J, Rodrigo $R$, Videla LA, Thielemann $L$, Orellana M, Pettinelli $P$, Poniachik J. Increase in long-chain polyunsaturated fatty acid $n-6 / n-3$ ratio in relation to hepatic steatosis in patients with non-alcoholic fatty liver disease. Clin Sci (Lond). 2004;106(6):635-43. https://doi.org/10.1042/ CS20030326.

78. Lee HS, Lee SJ, Yu HJ, Lee JH, Cho HY. Fermentation with Lactobacillus enhances the preventive effect of garlic extract on high fat diet-induced hepatic steatosis in mice. J Funct Foods. 2017;30:125-33. https://doi.org/10. 1016/j.jff.2016.12.043.

79. Nakamoto K, Takayama F, Mankura M, Hidaka Y, Egashira T, Ogino T, Kawasaki H, Mori A. Beneficial effects of fermented green tea extract in a rat model of non-alcoholic steatohepatitis. J Clin Biochem Nutr. 2009;44(3):23946. https://doi.org/10.3164/jcbn.08-256.

80. Lutz TA, Woods SC. Overview of animal models of obesity. Curr Protoc Pharmacol. 2012;Chapter 5:Unit5.61. https://doi.org/10.1002/0471141755. ph0561s58.

81. Masek J, Fabry P. High-fat diet and the development of obesity in albino rats. Experientia. 1959;15:444-5. https://doi.org/10.1007/BF02157708.

82. Oakes ND, Cooney GJ, Camilleri S, Chisholm DJ, Kraegen EW. Mechanisms of liver and muscle insulin resistance induced by chronic high-fat feeding. Diabetes. 1997;46(11):1768-74. https://doi.org/10.2337/diab.46.11.1768.

83. Hariri N, Thibault L. High-fat diet-induced obesity in animal models. Nutr Res Rev. 2010;23:270-99. https://doi.org/10.1017/S0954422410000168.

84. Clegg DJ, Gotoh K, Kemp C, Wortman MD, Benoit SC, Brown LM, D'Alessio D, Tso P, Seeley RJ, Woods SC. Consumption of a high-fat diet induces central insulin resistance independent of adiposity. Physiol Behav. 2011;103: 10-6. https://doi.org/10.1016/.jphysbeh.2011.01.010.

85. Storlien LH, Jenkins AB, Chisholm DJ, Pascoe WS, Khouri S, Kraegen EW. Influence of dietary fat composition on development of insulin resistance in rats. Relationship to muscle triglyceride and omega-3 fatty acids in muscle phospholipid. Diabetes. 1991;40(2):280-9. https://doi.org/10.2337/diab.40.2.280.

86. Toita R, Kawano T, Fujita S, Murata M, Kang JH. Increased hepatic inflammation in a normal-weight mouse after long-term high-fat diet feeding. J Toxicol Pathol. 2018;31(1):43-7. https://doi.org/10.1293/tox.2017-0038.

87. Miszta A, Kopec AK, Pant A, Holle LA, Byrnes JR, Lawrence DA, Hansen KC, Flick MJ, Luyendyk JP, de Laat B, Wolberg AS. A high-fat diet delays plasmin generation in a thrombomodulin-dependent manner in mice. Blood. 2002; 135(19):1704-17. https://doi.org/10.1182/blood.2019004267.

88. Echeverría F, Valenzuela R, Bustamante A, Álvarez D, Ortiz M, Espinosa A, Illesca P, Gonzalez-Mañan D, Videla LA. High-fat diet induces mouse liver steatosis with a concomitant decline in energy metabolism: attenuation by eicosapentaenoic acid (EPA) or hydroxytyrosol (HT) supplementation and the additive effects upon EPA and HT co-administration. Food Funct. 2019; 10(9):6170-83. https://doi.org/10.1039/c9fo01373c.

89. Berglund ED, Lustig DG, Baheza RA, Hasenour CM, Lee-Young RS, Donahue EP, Lynes SE, Swift LL, Charron MJ, Damon BM, Wasserman DH. Hepatic glucagon action is essential for exercise-induced reversal of mouse fatty liver. Diabetes. 2011;60(11):2720-9. https://doi.org/10.2337/db11-0455.

90. Storlien LH, Baur LA, Kriketos AD, Pan DA, Cooney GJ, Jenkins AB, Calvert GD, Campbell LV. Dietary fats and insulin action. Diabetologia. 1996;39:62131. https://doi.org/10.1007/BF00418533.

\section{Publisher's Note}

Springer Nature remains neutral with regard to jurisdictional claims in published maps and institutional affiliations.

Ready to submit your research? Choose BMC and benefit from:

- fast, convenient online submission

- thorough peer review by experienced researchers in your field

- rapid publication on acceptance

- support for research data, including large and complex data types

- gold Open Access which fosters wider collaboration and increased citations

- maximum visibility for your research: over $100 \mathrm{M}$ website views per year

At $\mathrm{BMC}$, research is always in progress.

Learn more biomedcentral.com/submission 